University of Redlands

\title{
Analyzing Optimal Locations for Food Delivery - A Case Study for Feeding America in Inland Empire, California
}

A Major Individual Project submitted in partial satisfaction of the requirements

for the degree of Master of Science in Geographic Information Systems

by

Faisal Ali A. Basudan

Ren Fang, Ph.D., Committee Chair

Mark Kumler, Ph.D.

December 2016 
Analyzing Optimal Locations for Food Delivery - A Case Study for Feeding America in Inland Empire, California

Copyright $(\subset 2016$

by

Faisal Ali A. Basudan 
The report of Faisal Ali A. Basudan is approved.

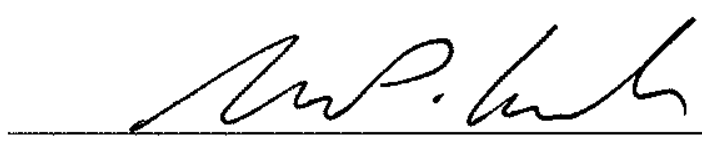

Mark Kumler, Ph.D.

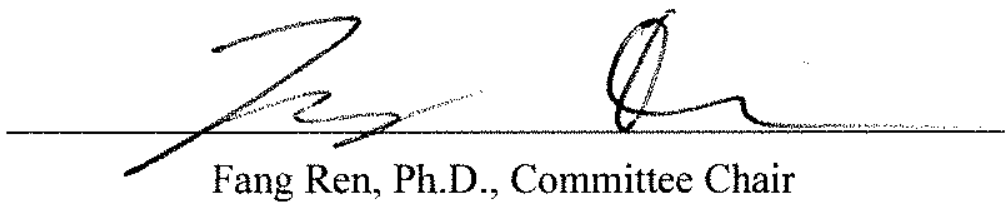

December 2016 



\section{Acknowledgements}

Thank you, Allah, for all Your grace and help toward my success. I could never have done this project without it being Your will. You have given me the strength and the patience to get my master's degree at last, after all the challenges and difficulties.

Next, and without delay, I must express my profound gratitude to a great lady-my mother, Mariam - for encouraging me to achieve my dream and to carry on with my education. Also, thank you to my lovely wife, Manahil, for providing me extraordinary support and continuous encouragement throughout my studies. I will be forever grateful for your love.

I would like to thank Prof. Fang Ren for her expert advice and support throughout this project. The door to Prof. Ren's office was always open whenever I had a question about my project, and I am indebted to her for her invaluable comments on my project.

This project would have been impossible without financial support from the government of my country, Kingdom of Saudi Arabia. Special thanks to the late King Abdullah bin Abdulaziz Al Saud, who offered me the unique opportunity to take my master's degree abroad, and to King Salman bin Abdulaziz Al Saud for his vital support.

Finally, I would like to thank the entire MS GIS faculty and all my classmates for their effort, guidance, and assistance during my two years with the program. 



\begin{abstract}
Analyzing Optimal Locations for Food Delivery - A Case Study for Feeding America in Inland Empire, California

by

Faisal Ali A. Basudan

Despite plentiful food sources, the cultural habits of wasting food have become an urgent global issue with too many people dying of starvation simply because of the lack of proper food availability. Feeding America Riverside | San Bernardino (FARSB) is one of many charities working to eliminate the problems of hunger and food waste in the Inland Empire of southern California. Although historically the organization has concentrated its efforts in the southwest area of the Inland Empire, FARSB now aspires to serve everyone in need within the entire Inland Empire.

This project focuses on three essential spatial problems. First, the optimal location for a second warehouse was established in order to extend the organization's distribution and maximize its coverage. This involved a series of spatial analyses and location models. Second, a web-based GIS application was developed to define the areas of greatest need and the most potential donors to increase the success of fundraising. That application included spatial data-based demographics that were represented in interactive, multiscale, and bivariate maps. Third, a web application was created for people in need to locate service providers within their neighborhood. The application was developed using Esri configurable apps to facilitate its accessibility for users. The project addressed several spatial problems using various GIS technologies in order to achieve the organization goals.
\end{abstract}




\section{Table of Contents}

Chapter 1 - Introduction ....................................................................................... 1

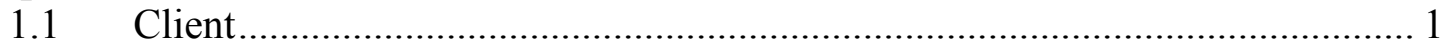

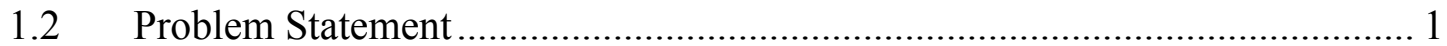

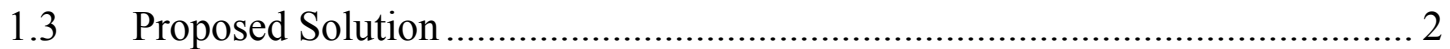

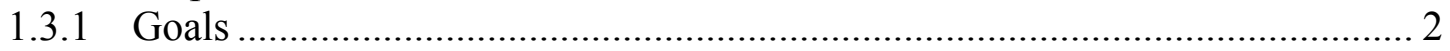

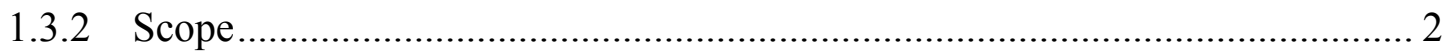

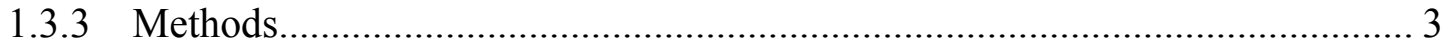

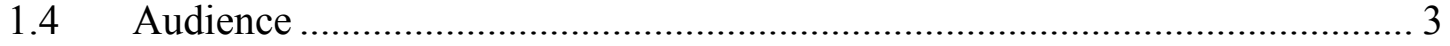

1.5 Overview of the Rest of this Report ........................................................... 4

Chapter 2 - Background and Literature Review .......................................................... 5

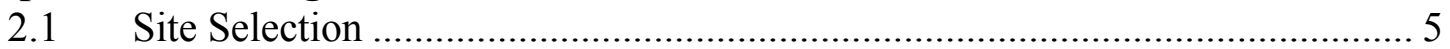

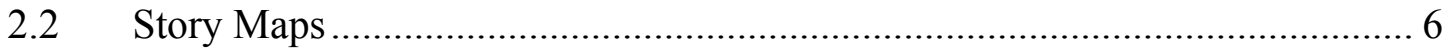

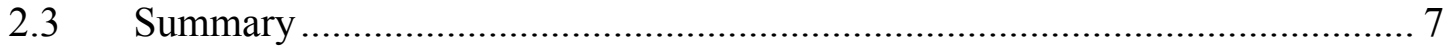

Chapter 3 - Systems Analysis and Design.......................................................9

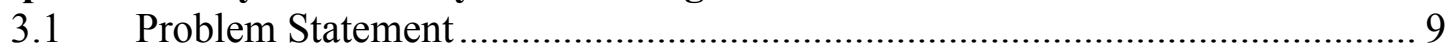

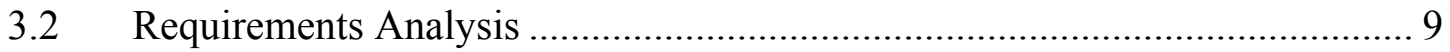

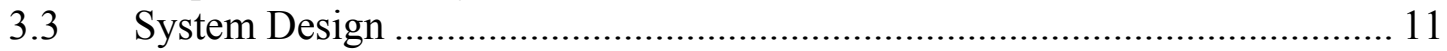

3.4 Project Plan ................................................................................... 12

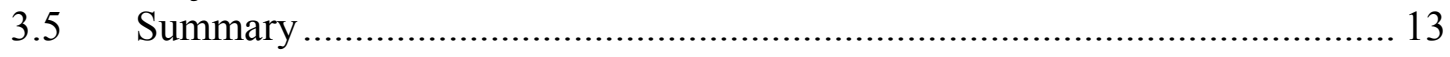

Chapter 4 - Database Design.................................................................................... 15

4.1 Conceptual Data Model .......................................................................... 15

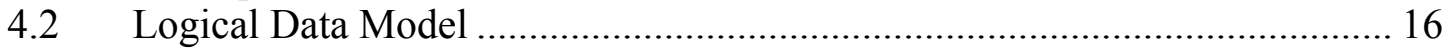

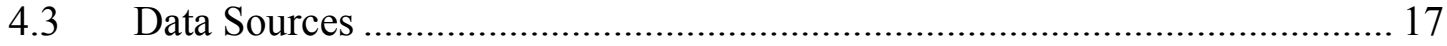

4.4 Data Scrubbing and Loading …………………….................................. 18

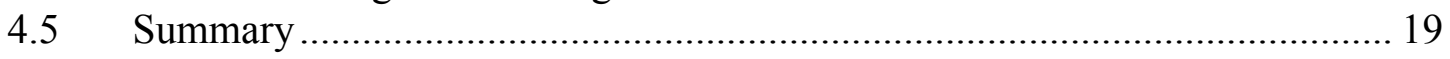

Chapter 5 - Implementation............................................................................................ 21

5.1 Analyzing Optimal Locations ................................................................. 21

5.1.1 Spatial Distribution and Service Areas ...................................................... 21

5.1.2 Selecting the Qualified Locations ................................................................ 23

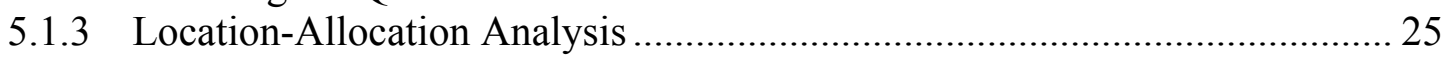

5.2 Donors Story Map ............................................................................... 29

5.2.1 Poverty and Food Stamps Web Map …………………................................ 29

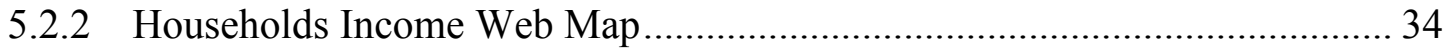

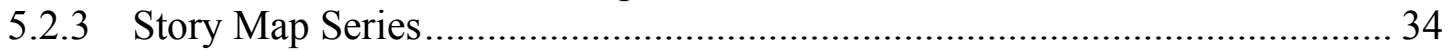

5.3 Agencies Story Map................................................................................... 34

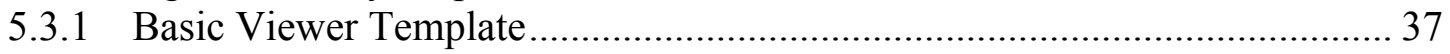

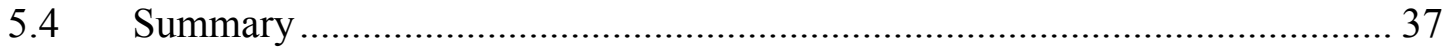

Chapter 6 - Results and Analysis.................................................................................39

$6.1 \quad$ Analyzing Optimal Locations …………………….................................. 39

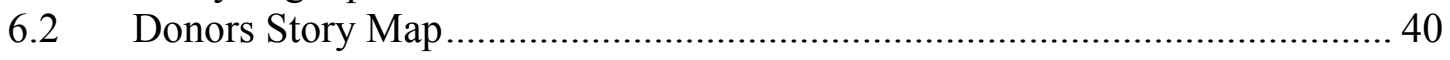

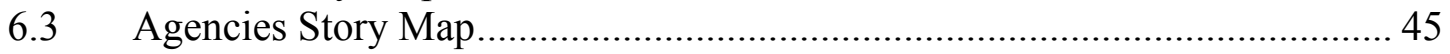




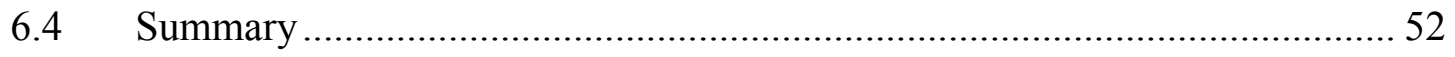

Chapter 7 - Conclusions and Future Work .................................................................... 53

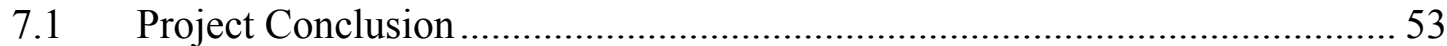

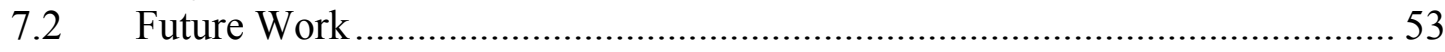

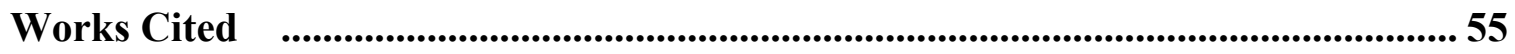





\section{Table of Figures}

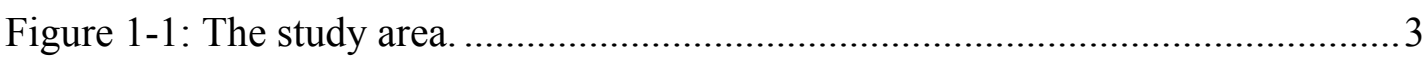

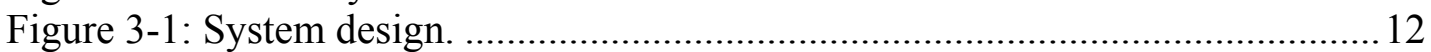

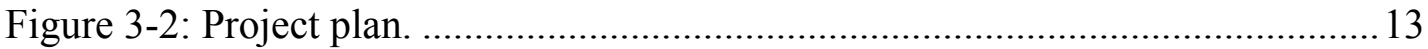

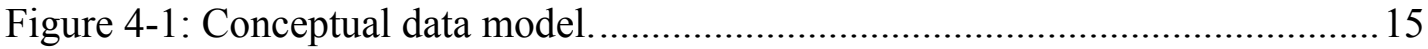

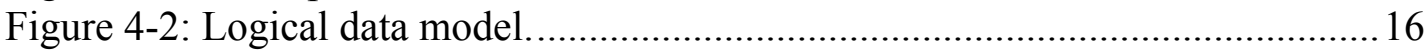

Figure 4-3: A screenshot of the Microsoft Excel spreadsheet. .................................... 18

Figure 5-1: The spatial distribution of the agencies and the warehouse.....................22

Figure 5-2: The service area within 30 minutes' drive from the warehouse. ….........23

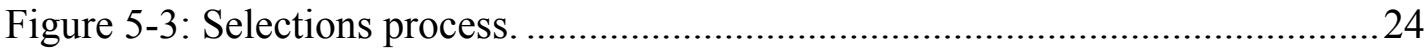

Figure 5-4: The concentrations of the underserved agencies...................................25

Figure 5-5: The parcels after the conversion to points. ………………………........26

Figure 5-6: The Minimize Facilities problem type...............................................2

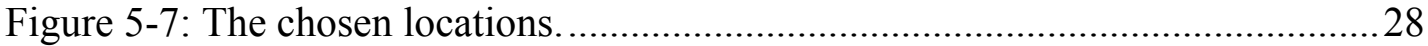

Figure 5-8: The Maximize Coverage problem type................................................2

Figure 5-9: The feature classes before and after the clip.......................................... 31

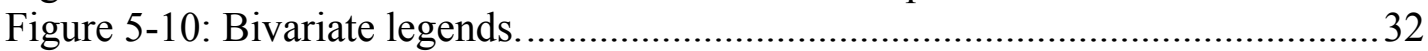

Figure 5-11: The congressional districts outlined legends. .......................................33

Figure 5-12: The new fields of the Congressional Districts feature class. ..................33

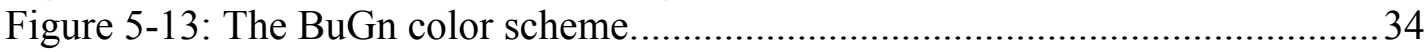

Figure 5-14: The icons of each group type and both scale levels..................................35

Figure 5-15: The web map showing agencies at the small scale level. .......................36

Figure 5-16: The web map showing agencies at the large scale level.......................36

Figure 6-1: The coverage of FARSB warehouse including the proposed location

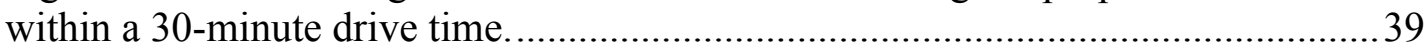

Figure 6-2: The interface of the donors story map. ………………………............4 40

Figure 6-3: The pop-up window of congressional district 8...................................4 41

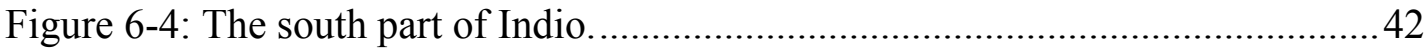

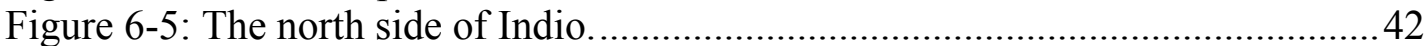

Figure 6-6: An example of the areas of greatest need. ............................................. 43

Figure 6-7: The interface of the donors story map while the Households Income map

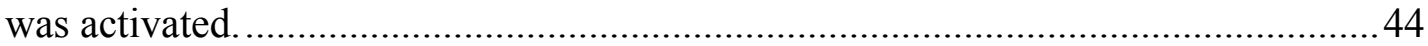

Figure 6-8: The pop-up window of the Lake Arrowhead area. ..................................45

Figure 6-9: The icons on the map at a small scale level..........................................46

Figure 6-10: The icons on the map at a large scale level........................................46

Figure 6-11: The pop-up window of the agencies story map. ………………...........4

Figure 6-12: The search bar with a suggestions list.................................................4

Figure 6-13: The agencies story map with all layers checked...................................49

Figure 6-14: The agencies story map with layers hidden.........................................49

Figure 6-15: The Basemap gallery tool of the agencies story map.............................50

Figure 6-16: The Details tool of the agencies story map...........................................51

Figure 6-17: The Share tool of the agencies story map..........................................51

Figure 6-18: The Print tool of the agencies story map.............................................52 



\section{List of Tables}

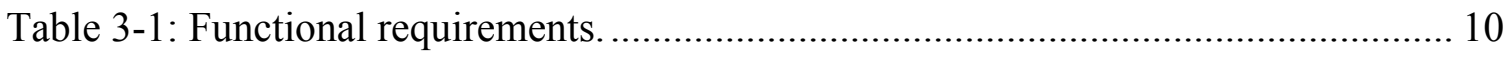

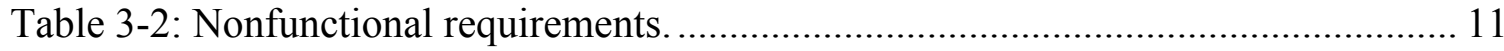

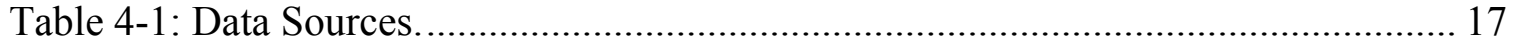

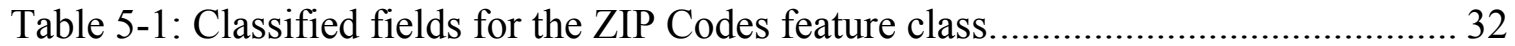

Table 5-2: Classified fields for the Congressional Districts feature class. ....................... 32 



\section{List of Acronyms and Definitions}

$\begin{array}{ll}\text { ACS } & \text { American Community Survey } \\ \text { CSV } & \text { Comma Separated Values } \\ \text { FARSB } & \text { Feeding America Riverside | San Bernardino } \\ \text { GIS } & \text { Geographic Information System } \\ \text { PNG } & \text { Portable Network Graphics } \\ \text { SDC } & \text { Smart Data Compression } \\ \text { SNAP } & \text { Supplemental Nutrition Assistance Program } \\ \text { URL } & \text { Uniform Resource Locator } \\ \text { VGI } & \text { Volunteered Geographic Information } \\ \text { ZIP } & \text { Zone Improvement Plan }\end{array}$





\section{Chapter 1 - Introduction}

Hunger is one of the most serious issues that the world now faces, and many nonprofit organizations are trying to mitigate this problem. Wasting food is another global problem despite the fact that there are so many other people living in hunger. Feeding America Riverside | San Bernardino (FARSB) is one of the many organizations that are trying to eliminate hunger in the Inland Empire, a region in Southern California that includes the counties of Riverside and San Bernardino. This project is a case study of FARSB and includes discussion about how its problems were solved using a variety of GIS technologies. This chapter consists of five sections in order to introduce the major aspects of this project. Section 1.1 provides information about the project's client. Section 1.2 discusses the problem statement, while Section 1.3 provides the proposed solution with three subsections: Goals, Scope, and Methods. Then, Section 1.4 defines the audience for this project and is followed by an overview of the rest of this project.

\subsection{Client}

The client for this project was Feeding America Riverside | San Bernardino (FARSB), which is "... a member of Feeding America, a nationwide network of food banks formerly known as Second Harvest" (FARSB, 2016). It is also an independent nonprofit 501(3) organization working on alleviating hunger issues in the Inland Empire of Southern California. The organization serves more than 600 charities and distributes more than 2.5 million pounds of food every month. More than 400,000 people per month receive food that is provided by FARSB.

William D. Carnegie, the president and CEO of the organization, was the point of contact for this project. According to Carnegie, the organization is charged with being a responsive and accountable partner to its donors of money and food, and is responsible for providing adequate food supplies to people in need within the Inland Empire. Moreover, the FARSB has to meet the Better Business Bureau standards for the operation of a charitable organization (Carnegie, personal communication, March 11, 2016). When the project began, the organization had only an 86,000 square-foot warehouse for receiving donated supplies, which would then be repacked and sent to the 600 agencies that in turn would distribute them to people in need.

\subsection{Problem Statement}

FARSB has been focused on the cities within Riverside and San Bernardino Counties, but that has left much of their rural areas underserved (Carnegie, personal communication, February 10, 2016). Also, the organization has been focused on fundraising through a fees-for-food structure instead of getting financial support by involving the community. Therefore, the organization needed to increase distribution and fundraising so that more underserved population in the Inland Empire has access to an adequate and nutritious food supply. Moreover, the organization was planning to establish a new warehouse to extend the food distribution. Thus, finding an optimal site that meets the required specifications was a fundamental problem that needed to be addressed in this project. 


\subsection{Proposed Solution}

GIS technology provides solutions for a variety of analyses and decision-making endeavors. For this project, creating web applications and implementing a locationallocation analysis were the proposed solutions based on the client's needs. The analyses would help the client in making the most appropriate decision to establish the second warehouse. The two proposed web applications would contribute to increasing the fundraising, which would lead to increasing food distribution as well.

\subsubsection{Goals}

The primary goal of this project was to employ GIS technology to identify the most suitable location for establishing a new warehouse. The secondary goal was to develop a web application that would show the locations of the organization's agencies along with their information, and to develop another web application that would visualize the areas of greatest needs and potential donors with some statistics. These applications would help the client raise public-awareness to get the community's attention and financial support.

\subsubsection{Scope}

The Inland Empire was the study area of this project. It consists of two counties in Southern California: San Bernardino and Riverside, as shown in Figure 1-1. This project was multifaceted, involving working on different platforms and producing multiple products. The primary platform to develop the web applications and to store the final products was ArcGIS Online per the client's request, while ArcGIS 10.3.1 for Desktop was the development platform to implement the required analysis and scrub the data. This project relied on data obtained from the client, Esri Demographics, Living Atlas of the World, and some other reliable sources. The deliverables included a web application that shows the locations of the organization's agencies, and another web application visualizing the areas of needs with some demographics and statistics. Moreover, the most important deliverable was a file geodatabase that included the most suitable site to establish the new warehouse. 


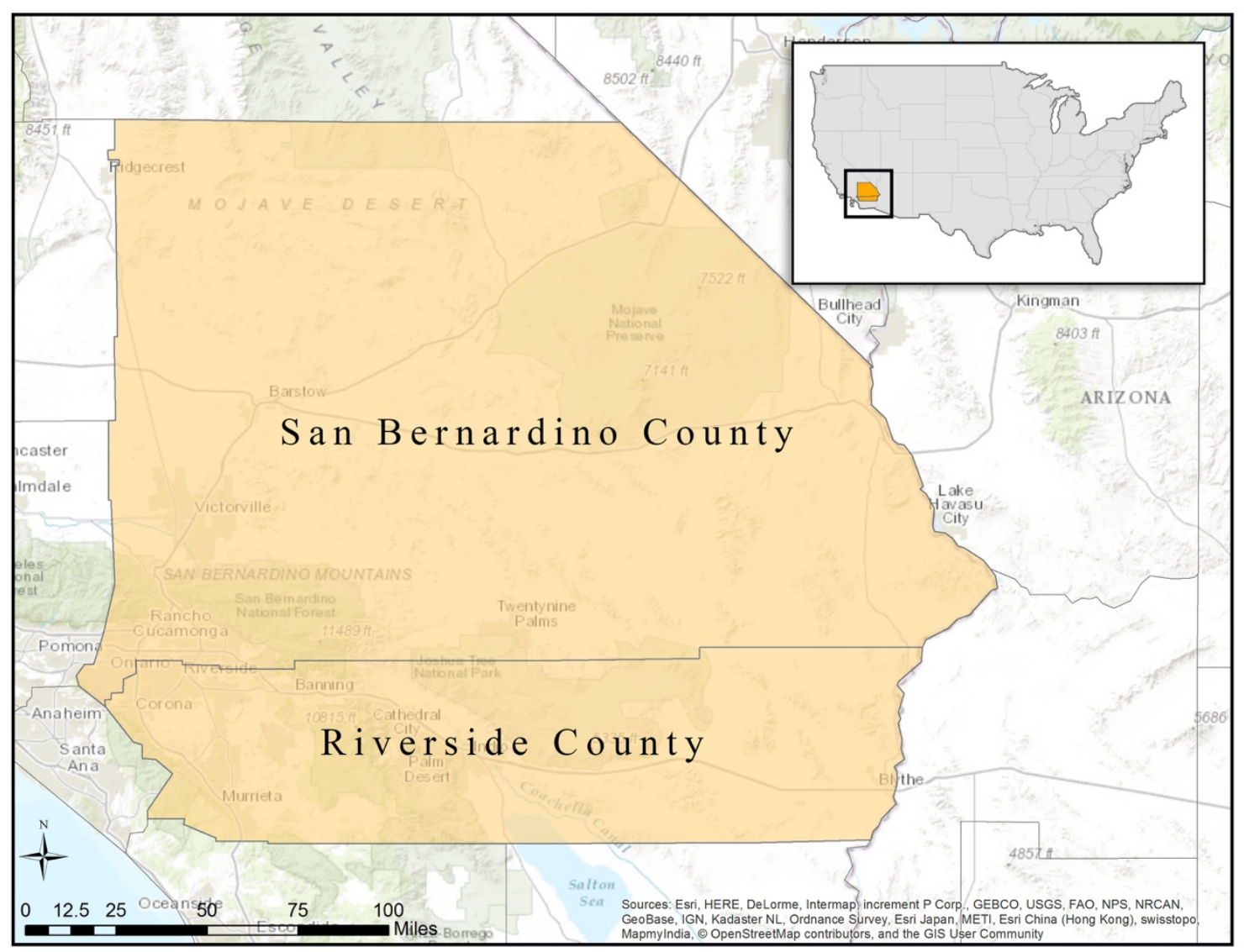

Figure 1-1: The study area.

\subsubsection{Methods}

This project utilized GIS technology to perform a series of analyses so that the client could find the suitable location for a new warehouse. These analyses went through a series of steps: first analyzing the spatial distribution of the agencies; then, analyzing the spatial correlation between the main warehouse and the agencies; and finally, analyzing the optimal location for the new warehouse. Kernel density analysis, a variety of network analysis models, and commonly used geoprocessing methods would be applied. For the web applications, ArcGIS Online geocoding would be used to map the current agencies and Configurable Apps for ArcGIS Online would be the platform to develop the two web applications.

\subsection{Audience}

The audience of this project was not only the FARSB but also other human services organizations in the Inland Empire and food banks across the United States. FARSB planned to use the project in a public-awareness campaign and to make it available for the public use. FARSB also intended to use this project "to foundation and corporate grants as well as government funding opportunities" (Carnegie, personal communication, February 10, 2016). 


\subsection{Overview of the Rest of this Report}

The following six chapters of this report go into great depth about different aspects of this project. Chapter 2 is the literature review, which reviews case studies and research that related to this project. Chapter 3 includes the system analysis and design of this project and it provides analysis requirements and the project plan. Chapter 4 discusses the data and the database design; also it covers the data sources and the process of preparing the data used in this project. Chapter 5 details the implementation and the actual work of the project and is followed by the final results in Chapter 6. Lastly, Chapter 7 concludes the project and provides suggestions for future work. 


\section{Chapter 2 - Background and Literature Review}

In order to determine the most appropriate solution for the client, previous related projects needed to be researched and reviewed to prove that the solutions implemented for this project were reasonable. This chapter discusses two major topics that have been addressed through this project: finding optimal locations for the client's food distribution center and using Esri Story Maps. Also, this chapter discusses various related case studies and examples that have concepts that are similar to this project. The chapter is divided into three sections: Site Selection, Story Maps, and Summary.

\subsection{Site Selection}

Finding optimal locations is an essential matter that would be of concern to many including business owners and people who are looking for a home. Each case is unique, so the factors and requirements vary from one case to another. Site selection should not be an arbitrary decision; it requires research and sometimes even studies, especially when it is for a business. Site selection plays a significant role in a business's success or failure.

Hernández and Bennison (2000) noted that the process of site selection historically has relied on intuition instead of knowledge-based methodologies, which have been available for many decades. However, the site selection process has undergone a transformation over the last decade (p. 357-367). That said, most third-world countries still use intuition much more than conscious reasoning, unlike first- and second-world countries, which have been using knowledge-based approaches to enhance the quality of site selection.

Due to the importance of emergency response for saving people lives, Li, Zhao, Zhu, and Wyatt (2011) reviewed "covering models and optimization techniques for emergency response facility location and planning, from the perspective of mathematical models and operations research. "The article discusses Emergency Medical Services (EMS) allocation problems, which are often problematic due to the problems' complexity, in addition to several covering models such as Double Standard Model (DSM), Location Set Covering Problem (LSCP), Maximum Availability Location Problem (MALP), Maximal Covering Location Problem (MCLP), and Maximum Expected Covering Location Problem (MEXCLP) models. The authors divided the emergency facility location problems into three broad groups: covering models, $p$-median models, and $p$-center models. (Li, Zhao, Zhu, \& Wyatt, 2011).

An article by Tong, Ren, and Mack (2012) discussed the site selection problem for farmers' markets. Unlike grocery stores, farmers' markets operate with very limited hours and are distributed sparsely in space. To maximize the accessibility to these markets, the authors proposed a new approach by considering the temporal constraints that people experience in their daily activity-travel and multi-stop trip chains. With a case study in Tucson, Arizona, two models were implemented to locate farmers' markets and the associate operating times. The results show that total travel distances to the markets are reduced when individual activity programs are considered into the site selection models. (Tong, Ren, \& Mack, 2012). 
Esri (2016a) provided a case study that is similar to this project. In this case study, the most suitable sites for a food distribution center were identified by using three different types of Esri software: ArcGIS Online, ArcGIS for Desktop, and ArcGIS Pro. The distribution center needed to serve a chain of neighborhood grocery stores. The owners had already determined one potential site and were searching for others. The owners identified the center's criteria, and they began selecting sites that matched each criterion. In the final analysis, they found over 17,000 sites; however, the number was narrowed down to ten potential sites by using a series of attribute and spatial selections in ArcGIS. This analysis helped the decision-makers determine the optimal site.

Esri (2016b) provided another case study that presents a workflow to identify parcels that would be suitable for a new fire station within a particular city. The workflow uses several approaches such as attribute and spatial selections, network analysis, and raster analysis within the ArcGIS suite. The city had only three fire stations, and the director of public safety and the city council members were looking to enhance coverage by constructing a new fire station. After a couple of meetings, the criteria and data requirements were determined. Ultimately, out of 15,000 candidate sites, the group found eight as being suitable.

As another case study based on the previous one, Esri (2016c) presented an overview of how the decision-makers determined two optimal sites from among the eight locations. At that stage of the analysis, the group used location-allocation and service area tools to identify the optimal sites; moreover, they considered travel time to maximize the fire department's coverage. In the final analysis, one optimal site was chosen as well as a backup site in case of need.

Another case study that was presented by Esri (2016d) involved improving water quality monitoring. The environmental quality control department wanted to observe the connection between livestock grazing areas and the state's water quality. Earlier studies by the department emphasized that streams that flow through grazing areas can be polluted by sediment and animal waste. The biologists used ArcGIS to make a data layer with the grazing allotments organized by hydrologic basin, which helped to quickly search the layer's table to get a list of all the allotments in a particular basin. Ultimately, the biologists assigned the grazing allotments information to each stream, which would help to trace pollutants back to the correct allotments in case field tests found a water quality problem with a particular stream.

\subsection{Story Maps}

Over the past few years, ArcGIS has been evolving in such a way that Web GIS is emerging as a platform that end users can use to deliver geographic information by creating maps and implementing analytics (Fu, 2015, p. ix). While maps and stories complement each other, until recently they had not been produced as one thing; however, the fusion of maps and stories becomes available with Esri Story Maps (Harder, 2015, p. 37). Story Maps is an Esri web mapping application that combines the power of maps and storytelling; also, it provides "a great way to quickly build useful and attractive information products tailored to your organization's needs" (Esri, 2013). Esri is providing useful templates that facilitate creating story maps, which combine interactive maps with multimedia to inform, engage, and inspire the audience (Anness, 2014). Since Story 
Maps was introduced, it has become a platform that presents stories for business, education, environmental reports, and many other purposes in various fields.

According to the U.S. Census Bureau, "The poverty rate is one of several socioeconomic indicators used by policy makers to evaluate economic conditions" (as cited in Herries, 2014). Herries (2014) wanted to evaluate the economic situation of the United States. He created a story map that presents the ratio of US households existing above and below the poverty line. The story map contained a multi scale map for four geographic units - states, counties, tracts, and block groups - to represent the ratio at each scale level. He found that, overall, there were 6.2 households above the poverty line for each household below it.

Another example of telling story about poverty was created by Bell (2014). She emphasized that "poverty must be understood and approached as a multidimensional issue" because it has many facets such as inadequate health care, income, housing, and education and lack of safe drinking water. She created a story map that showed the Multidimensional Poverty Index (MPI) for 108 countries around the globe. She used Esri Story Map Journal, which includes several slides enriched by expressive multimedia, statistics, and interactive maps.

Brooks-Gunn and Duncan (1977) stated that children living in poverty have little prospect of completing school (p. 55). Trinh (2014) created a significant story map that tells how the level of education attainment correlates to living in poverty. Esri Story Map Swipe was used with statistics and interactive maps to compare the percentage of people living in poverty and the level of education attained by residents of Grand Rapids, Michigan. The results were not surprising: most of the people without a high school diploma or higher education are living in poverty-stricken areas.

The Esri Story Maps Team (2015) wanted to examine the gap between minimumwage income and the amount needed to meet a minimum standard of living in the United States. The Living Wage Calculator was developed by professor Amy Glasmeier of Massachusetts Institute of Technology to help identify the gap between minimum wages and the cost of living. The Esri team customized the story map by using the JavaScript programming language. The story map included two different maps, one at the county level and other at the city level, and each map was enriched with the statistics of three types of variables: cost of living, minimum wage, and the gap between the two.

\subsection{Summary}

In brief, this chapter has discussed some topics that have been addressed through this project. The topics were to identify optimal locations, and to use Esri's Story Maps to present diverse interactive spatial information. Also, this chapter included useful case studies and examples. While each case has a different concept, requirements, and audience, most of the solutions were within the GIS domain. The case studies were used to help determine the best solution for selecting the optimal food distribution center locations, also proving the efficiency of using story maps for this kind of project. 



\section{Chapter 3 - Systems Analysis and Design}

Understanding the problem and requirements of any project is the crux to satisfying the client's expectations, so identifying them in advance helps to recognize any buried risks. This chapter discusses the system analysis and design and is divided into five sections. In Section 3.1, the problem statement gives the reader an idea about the problem that was addressed by this project. Second, in section 3.2, the requirements analysis discusses both the functional and nonfunctional requirements of the project. Third, Section 3.3, is about the system design that represents the structure of the project's system and its essential components. Section 3.4 explains how a project plan provides an overall view of the project, and an analysis of that plan versus reality. Lastly, Section 3.5 provides a summary and conclusion of this chapter.

\subsection{Problem Statement}

Carnegie (2016) noted "Feeding America Riverside | San Bernardino Counties [FARSB] began in 1980 as Survive Food Bank in response to the increasing concern about the dual problems of hunger and food waste in the Inland Empire." Currently, FARSB is the primary source of food for over 600 charities, and over 425,000 people rely on the food that is provided by the organization every month. While the organization has been serving the area since 1980, it has been focused on the cities of Riverside and San Bernardino, and that has left much of regions underserved. Also, the organization has been focused on raising funds through a fees-for-food structure rather than by getting financial support by engaging the community (Carnegie, personal communication, February 10,2016). Therefore, the organization wanted to increase the distribution and fundraising so that everyone in the Inland Empire has access to affordable healthy food. Moreover, the organization was planning to establish a new warehouse to extend food distribution. Finding an optimal location that would meet the required specifications was the fundamental problem that needed to be addressed in this project.

\subsection{Requirements Analysis}

Identifying the requirements was an essential step to understanding the goals of this project. The requirements were discussed with the client in advance in order to understand his expectations in the final products. The requirements were divided into two groups: functional and nonfunctional. The functional requirements describe how the system would behave and respond to meet the user's needs, whereas the non-functional requirements describe the attributes and characteristics of the system. The functional and nonfunctional requirements for this project are listed in the following tables. 
Table 3-1: Functional requirements.

\begin{tabular}{|l|l|}
\hline Requirements & Description \\
\hline Pop-up Window & $\begin{array}{l}\text { The story maps should have interactive maps that allow end users } \\
\text { to click on each point to see brief details. }\end{array}$ \\
\hline Search Capability & $\begin{array}{l}\text { The search tool must allow end users to search by ZIP code and } \\
\text { agency types. }\end{array}$ \\
\hline Legend & Each map in the story maps must have a legend. \\
\hline Basemap Gallery & End users must be able to change the basemap in the story map. \\
\hline Zoom & $\begin{array}{l}\text { End users should be allowed to zoom in and out to explore the } \\
\text { maps. }\end{array}$ \\
\hline Find My Location & $\begin{array}{l}\text { End users must be able to find their current location on the maps } \\
\text { so that they can find the agencies within their area. }\end{array}$ \\
\hline Multiscale & $\begin{array}{l}\text { When end users zoom in to a particular scale level, the } \\
\text { geographic unit has to be changed from districts to ZIP codes and } \\
\text { vice versa when zooming out. }\end{array}$ \\
\hline Sharing & End users must be able to share the links of the story maps. \\
\hline
\end{tabular}

The functional requirements include eight requirements for two web applications. Five functional requirements were determined for both web applications: Pop-up Window, Legend, Zoom, Find My Location, and Sharing. Search Capability and Basemap Gallery functional requirements were determined for one of the web applications (Agencies Story Map), whereas Multiscale functional requirement was determined for the other web application (Donors Story Map). All functional requirements were determined to enable end users to interact with the applications. 
Table 3-2: Nonfunctional requirements.

\begin{tabular}{|l|l|}
\hline Requirements & Description \\
\hline Configuration & The client must be able to edit the story maps. \\
\hline Accessibility & $\begin{array}{l}\text { End users should be allowed to access the story maps through } \\
\text { web browsers and an internet connection with no need of having } \\
\text { an ArcGIS Online account. }\end{array}$ \\
\hline $\begin{array}{l}\text { Geodatabase and } \\
\text { Map Package }\end{array}$ & $\begin{array}{l}\text { The client must be able to see the final results of the analysis in } \\
\text { ArcGIS for Desktop as a geodatabase and map package. }\end{array}$ \\
\hline Client's Account & $\begin{array}{l}\text { The story maps must be hosted in the client's ArcGIS Online } \\
\text { account. }\end{array}$ \\
\hline Coordinate System & $\begin{array}{l}\text { NAD_1983_StatePlane_California_V_FIPS_0405_Feet must be } \\
\text { the coordinate system for the geodatabase of the analysis in } \\
\text { ArcGIS for Desktop. }\end{array}$ \\
\hline
\end{tabular}

The nonfunctional requirements include five requirements for the web applications and locational analysis. Three nonfunctional requirements were determined for the web applications: Configuration, Accessibility, Client's account. While Geodatabase and Map Package, and Coordinate System were the other two nonfunctional requirements that were determined for the locational analysis.

\subsection{System Design}

System design helps to get a better understanding of the project's structure, and provides an overall view of the technologies that will be used in the project. The system design of this project was created based on the project requirements. It was divided into two main components, which are demonstrated in Figure 3-1. The first component was the analysis within ArcGIS for Desktop, while the second component was the web applications. 


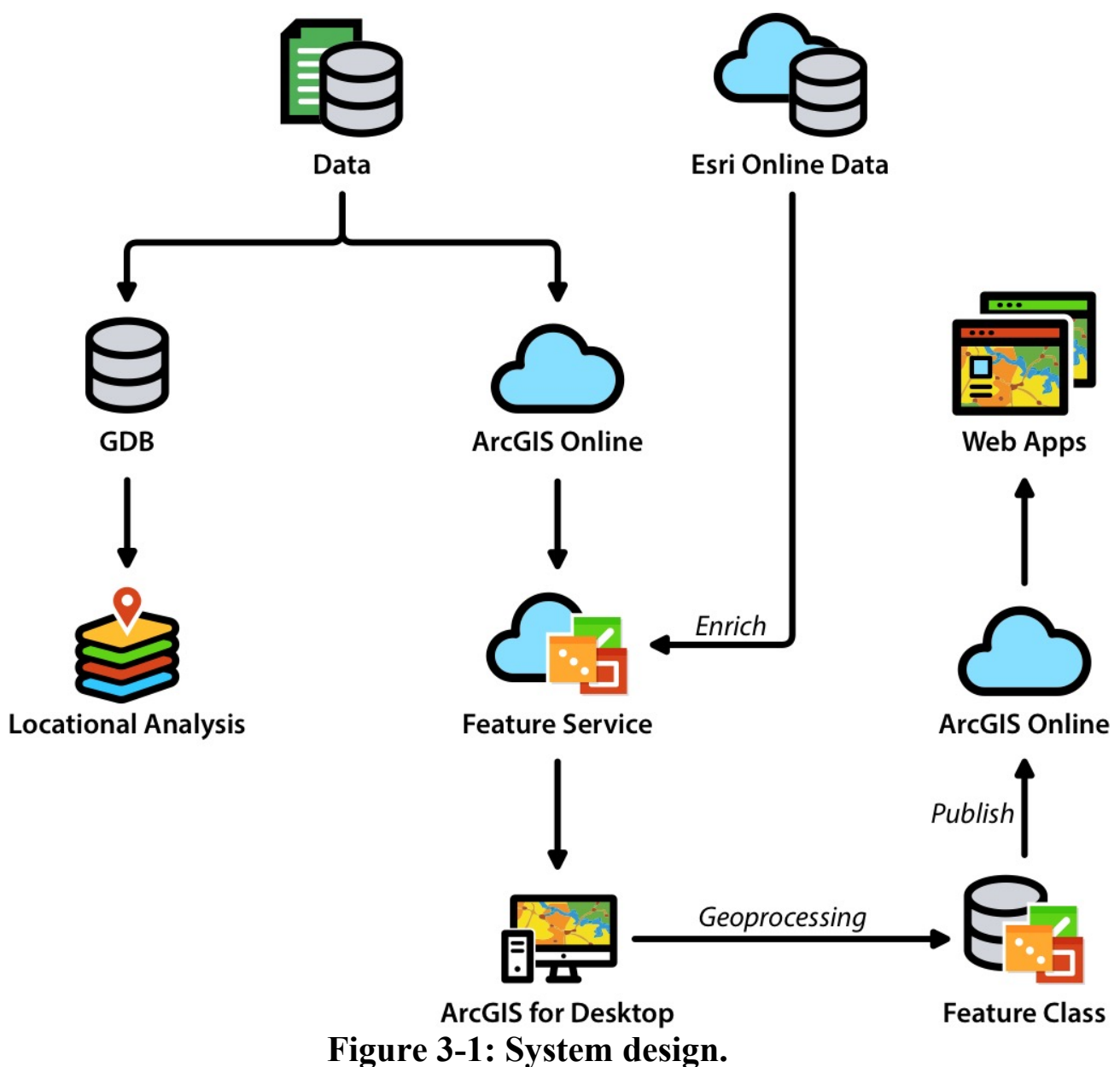

The data that were obtained from the client and other sources were moved into a geodatabase to conduct the analysis and provide the results to the client. The client's data were also used in ArcGIS Online to create one of the web applications. Other data obtained from Esri needed to be enriched by Esri Demographics that are available in ArcGIS Online. However, after enriching the feature services, it was necessary to move and scrub them in ArcGIS for Desktop due to the software's powerful functionality to enhance the data structure. Afterwards, the data was published to ArcGIS Online to create the web applications and host them in the client's account.

\subsection{Project Plan}

Having a feasible project plan can ensure progress within a required timeline. Although this project's plan helped maintain progress, there were unexpected technical difficulties, data unavailability, and task changes. The biggest factor that impacted the plan was data availability, which forced some tasks to be changed. It was expected that all of the data would be obtained from the client; however, the only data that were provided was a Microsoft Excel spreadsheet with the organization's agencies' information, and the rest of the data were obtained from different sources that will be listed in the next chapter. 


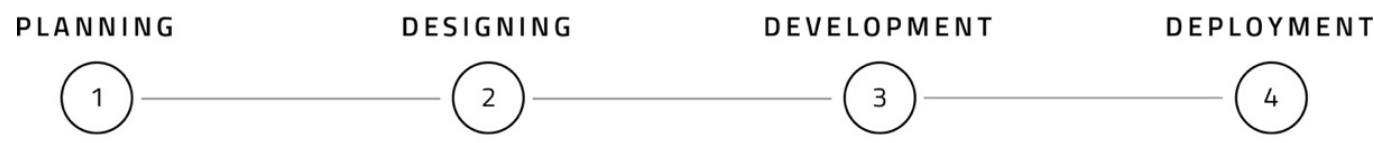

Figure 3-2: Project plan.

The plan for this project had four phases, and each one included various tasks (Figure 3-2). The plan started with the planning phase; during meetings with the client, the study area, goals, scope, and required data were identified. This phase also involved analyzing the solutions and risks, and receiving the client's data. Next was the designing phase, which included the data research and studying the tools and methods that would be used throughout the project and preparing the dataset to be ready for use in the next phase. Following that was the development phase, which included the practical tasks of the project. In this phase, the analysis was conducted, the results were approved, and the story maps were created, tested, and approved. Lastly, in the deployment phase, the story maps were hosted in the client's ArcGIS Online account and the results of the analysis were provided to the client. Moreover, the required documentations were provided to the faculty and approved.

In conclusion, although this project plan was altered, it still was very beneficial to understand its value for the future projects.

\subsection{Summary}

This chapter addressed the system analysis and design, which is divided into five sections: the problem statement, functional and nonfunctional requirements, system design, and project plan. Each section described the project system and design and provided details and specifications of the project. 


\section{Chapter 4 - Database Design}

This chapter discusses the database design and everything about the data that was used in this project. The conceptual data model and the relationships among the data entities are explained in Section 4.1. Section 4.2 is about the logical data model and includes more details about the actual structure of the database. Since many different sources of the data were used for this project, section 4.3 contains a list of those sources. Finally, section 4.4 discusses the data cleaning and loading and is followed by a summary of this chapter.

\subsection{Conceptual Data Model}

A conceptual data model is a visual descriptive model that shows the most important entities in the project database and the relationships among them. Using a conceptual data model is one of the most common ways of providing an overall idea and a broad overview of the major components of a project database without going much into the details. Figure 4-1 illustrates the conceptual data model for this project and will be followed by greater description about the model.

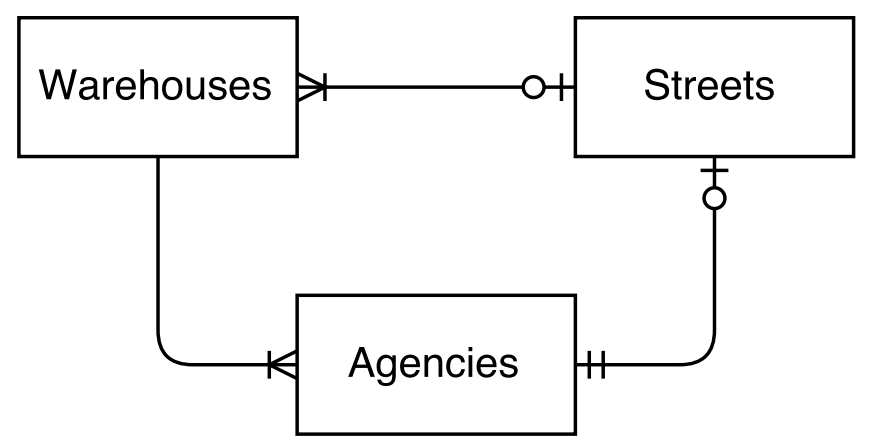

Figure 4-1: Conceptual data model.

This Unified Modeling Language diagram was created to show the conceptual data model for this project, and it contains three major entities: Agencies or charities, Streets, and Warehouses. The Agencies entity included all of the client's agencies that are receiving food delivered from the client's warehouse. The Agencies will then distribute food to individuals that need the help. The food is transported from the client's warehouse to the agencies; therefore, the streets entity was used as a link between them. Also, the Streets entity was used in the analysis to identify the required service from the warehouse. The Warehouses entity included the existing warehouse of the client and all the candidate sites that were to come out of the analysis. 


\subsection{Logical Data Model}

While the conceptual data model showed a general overview of the important entities and the relationships among them, the logical data model represents the actual data structure with more details of its content and their relationships. ArcCatalog 10.3.1 was used to organize and design the database, as shown in Figure 4-2.

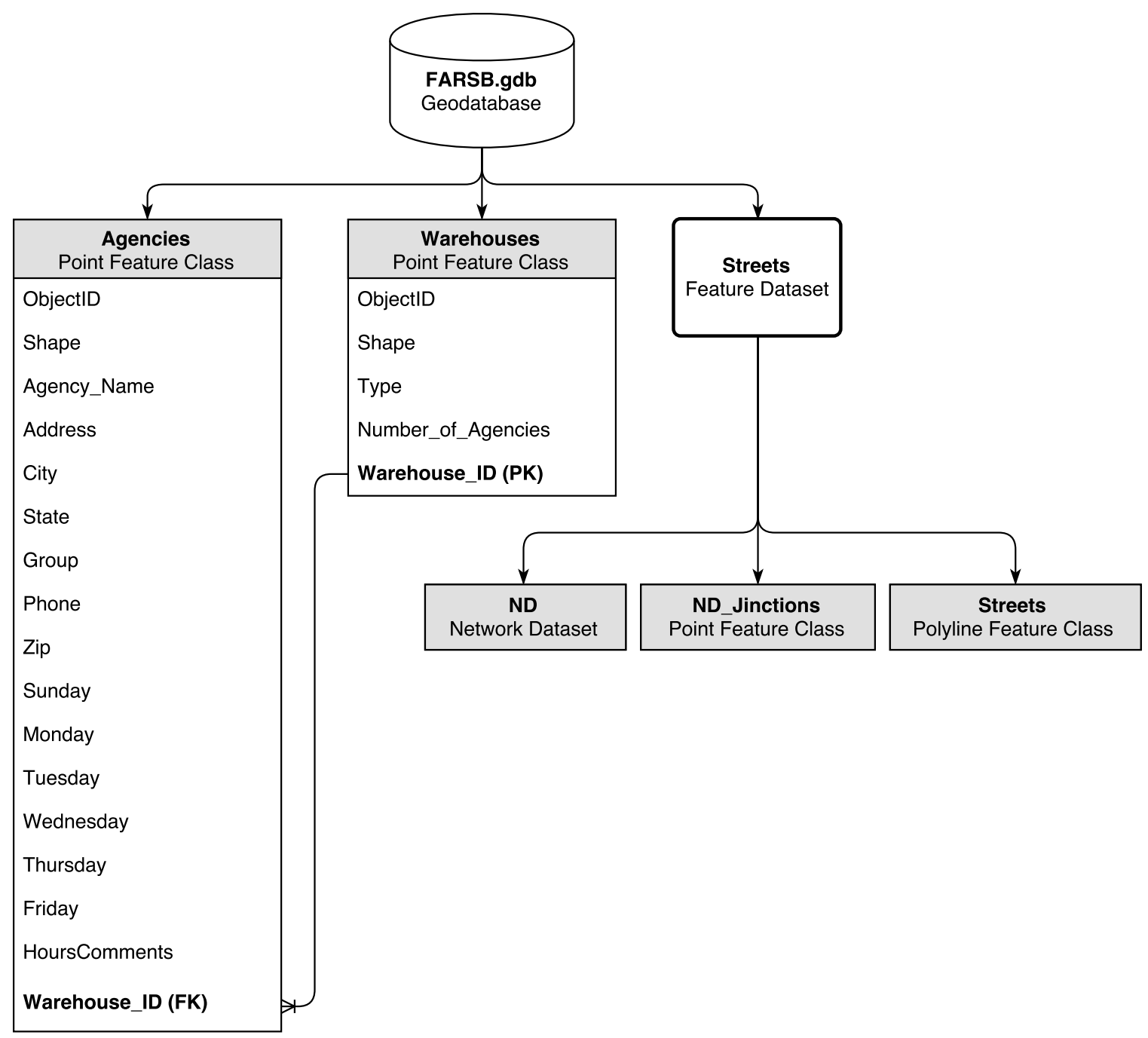

Figure 4-2: Logical data model.

The database of this project had two feature classes - Agencies and Warehouseswhich were stored in a single file geodatabase, FARSB. Also the file geodatabase included a Streets feature dataset that contained ND network dataset, ND Junctions point feature class, and Street polyline feature class. The Agencies feature class had 17 fields and contained information about 360 agencies. The Warehouses feature class was the output of a combination of multiple feature classes; it included four different fields and 328 points that represent the sites for warehouses in the Inland Empire that meet the client's specifications. The Type field included four different types of warehouses: 
Qualified, Candidate, Existing, and Optimal; each type will be outlined in the following chapters. The Number of Agencies field contained the number of agencies that are served by a warehouse within 30 minutes, the limit for a desired driving specified by the client. The feature classes were related to each other; one warehouse could serve many agencies, while one agency could be served by one warehouse. The both feature classes had Warehouse ID field, that field was the link of the relationship between the feature classes. This relationship would help the client to select the served agencies by a warehouse.

\subsection{Data Sources}

Data is the most critical component in GIS projects; it plays a significant role in their success. Without having proper data, it would be a big challenge to complete the project and achieve the client's goals. As mentioned in the previous chapter, the project's scope had to be changed due to the lack of data. Because the client did not have all the data required for the project, it was necessary to find other sources to obtain the needed data. The study area of this project included two different counties-Riverside and San Bernardino - so it was challenging to find data from a single source in addition to having a variety of data domains. The project data was used for two purposes. Some of the data was used for the analysis and stored in a file geodatabase, as mentioned in the previous section. The other data was used for the story maps that were hosted in the client's ArcGIS Online account. Table 4-1 provides a list of all the data sources and it is followed by more details.

Table 4-1: Data Sources.

\begin{tabular}{|l|l|l|}
\hline Dataset & Source & Purpose \\
\hline Agencies & Client & Analysis and Story Maps \\
\hline Boundaries & Esri & Analysis and Story Maps \\
\hline Demographics & American Community Survey (ACS) & Story Maps \\
\hline Streets & Esri & Analysis \\
\hline Land Use & Riverside County Planning & Analysis \\
\hline Land Use & Riverside County Assessor & Analysis \\
\hline Land Use & County of San Bernardino & Analysis \\
\hline Land Use & San Bernardino City Hall & Analysis \\
\hline Land Use & Trimble & Analysis \\
\hline Parcels & Riverside County & Analysis \\
\hline Parcels & County of San Bernardino & Analysis \\
\hline
\end{tabular}

The client provided the data of the organization's agencies in a Microsoft Excel spreadsheet that included the agencies' names, addresses, and operation hours, as shown in Figure 4-3. While the client's organization serves over 600 agencies, the data only included 360 agencies due to they are not open to the public, such as residences, rehabilitation centers, and children's shelters. Esri's streets dataset was obtained from the Center of Spatial Studies in the University of Redlands. 


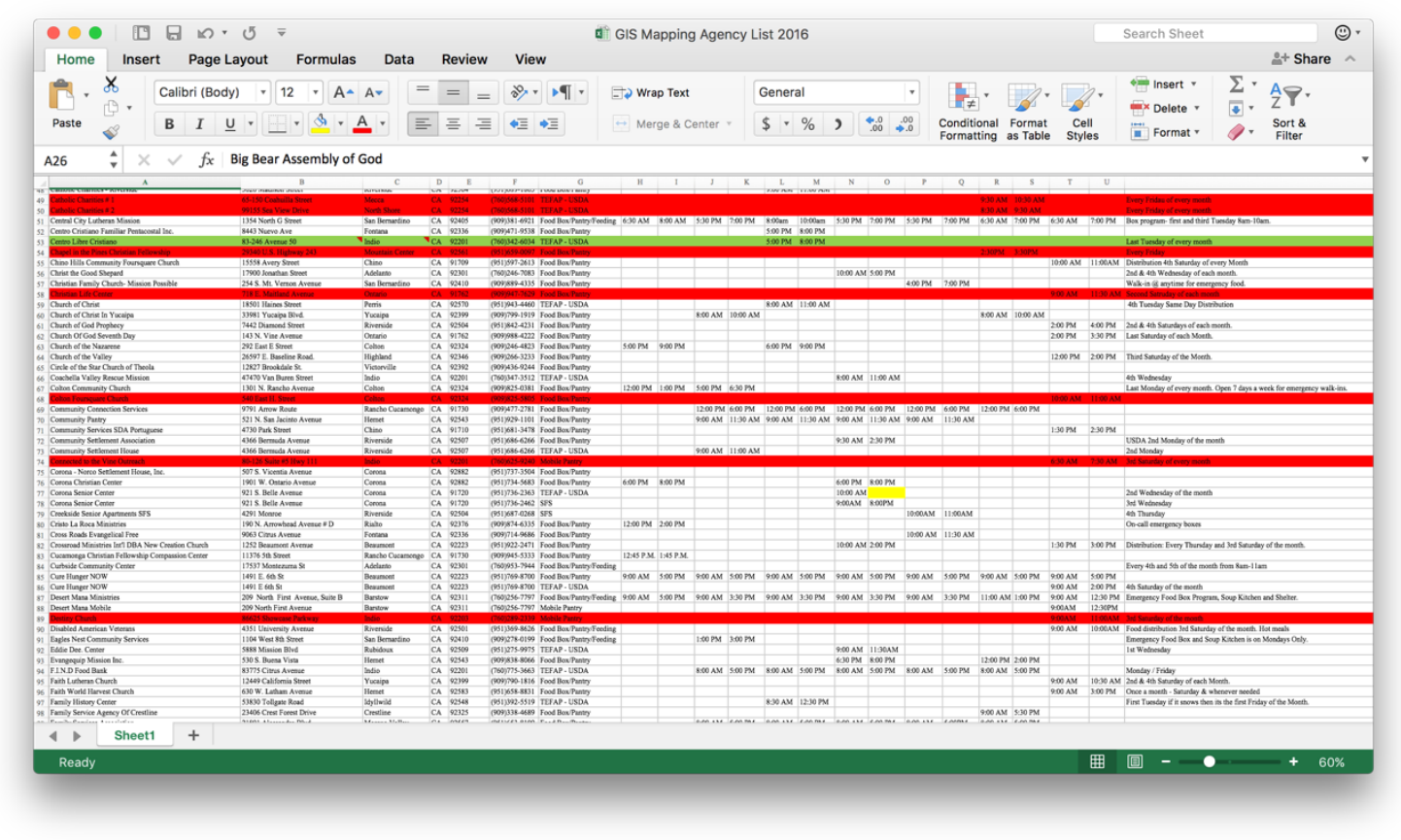

Figure 4-3: A screenshot of the Microsoft Excel spreadsheet.

Esri provides many sources of online GIS data. The Living Atlas of the World is an Esri collection of reliable and ready-to-use data. It was the source of the boundaries data, such as ZIP codes, congressional districts, and counties; which were created by Esri Data and Maps. The client wanted to map socioeconomic information for the ZIP code and congressional district levels within the Inland Empire; the source for this information was the American Community Survey (ACS). This data was hosted and provided by Esri Demographics within ArcGIS Online.

Since the study area has two different counties, the land-use data was a combination of multiple datasets due to there was no single source of this kind of data for the whole study area. There were five different sources of the land-use data: Riverside County Planning, Riverside County Assessor, County of San Bernardino, San Bernardino City Hall, and Trimble Data Marketplace. Not only the land-use data but also the parcels data were a combination of two datasets from different sources-Riverside County and County of San Bernardino.

\subsection{Data Scrubbing and Loading}

After receiving the client's data, it was necessary to check its accuracy and quality. Some defects were discovered upon data inspection, so all of the defects were marked and sent back to the client for correction. The data went back and forth a couple of times until it was ready for the next step; furthermore, it was exported in a CSV file so that it could be used in ArcGIS for Desktop. The exported data was not ready to use because it did not have $\mathrm{x}, \mathrm{y}$ coordinates; therefore, geocoding the data was essential. The CSV file was loaded into ArcGIS for Desktop in order to geocode the addresses by using the World Geocoding Service (ArcGIS Online). Eventually, the agencies data was loaded into a file geodatabase as a feature class. 
The streets data included the entire United States and Canada as a Smart Data Compression (SDC) feature class, so it was converted to a feature class and clipped to the Inland Empire boundary via ArcGIS for Desktop in order to have only the streets within the study area. The client wanted to identify the Inland Empire zones that are suitable for warehouses so the new warehouse could be in that zone. Each feature class of the Land Use dataset had different types due to the variety of the sources; therefore, the client made revisions and determined all the appropriate types. Ultimately, all the feature classes were fused into a single feature class to facilitate use in the analysis.

To achieve the client's goal of finding the optimal location, it was important to have the locations at the detailed parcel level. The land-use datasets included only general zoning details; therefore, the parcels dataset was used as a basis to select the locations based on the required criteria. There were two different feature classes of the parcels dataset: Riverside County and San Bernardino County; therefore, they were combined into a single feature class.

Due to the variety of the data sources, some of the data were not projected, and some had a different coordinate system. Because the study area of this project was the entire Inland Empire, the geodatabase was projected in the NAD_1983_StatePlane_California_V_FIPS_0405_Feet coordinate system. This coordinate system was the most appropriate one in order to reduce the distortion of the study area.

\subsection{Summary}

A database is a crucial component of a project's success. Section 4.1 and 4.2 discussed the conceptual and logical data models that were used in this project and which provided an overview of the database structure. This project had a diversity of data sources; the third section discussed the sources that the data was derived from. Lastly, because of the sources' diversity and how the data was not ready to use, the fourth section discussed all the data scrubbing that had to be done before the implementation phase. 



\section{Chapter 5 - Implementation}

The implementation chapter discusses the methodologies that were applied in this project to reach the goal of the final information products. There are three major components in this chapter. The most significant part in this project is described in section 5.1Analyzing Optimal Locations, which discusses how the analysis was conducted and provides some details about the process and the tools that were used. It is divided into three subsections: Spatial Distribution and Service Analysis, Selecting the Qualified Locations, and Location-Allocation Analysis. Section 5.2-Donors Story Map discusses the methodology of creating a story map, and it is divided into three main subsections. The first, Poverty and Food Stamps Web Map, discusses the process of creating a multiscale and bivariate map, as well as creating matrix legends that were displayed in pop-up windows. The second subsection is Households Income Web Map, and the last subsection is Story Map Series. Section 5.3 discusses the Agencies Story Map and the custom icons that were created using a design software. Lastly, Section 5.4 summarizes this chapter.

\subsection{Analyzing Optimal Locations}

One of the project's goals was to increase the organization's food distribution as much as possible. While the organization had a single warehouse, located in the city of Riverside, the client was planning to establish a new warehouse in order to extend the distribution area. Although the current warehouse had been serving all of the organization's agencies, the client desired to have the majority of them within a 30-minute driving distance to protect the integrity of refrigerated and frozen food products during delivery. Identifying the optimal site for a second warehouse that would maximize coverage within 30-minute drive times was the most significant issue; it was addressed through several stages, which will be outlined in the following subsections. Before commencing, the criteria of the new site had to be determined. The client defined four criteria for the new location. It had to be:

- From three to five acres;

- Within one-half mile of major highways;

- In an area zoned for warehouses;

- Within the concentration of underserved agencies.

\subsubsection{Spatial Distribution and Service Areas}

In order to identify the optimal location for the new warehouse, the spatial distribution of the agencies in relation to the existing warehouse was analyzed. Kernel density estimation is an approach to visualizing the spatial distribution of a set of points by calculating the point density within a predefined kernel. The Kernel Density tool in ArcGIS was used to analyze the spatial distribution of the agencies. The majority of the agencies were found to be concentrated in the southwest of the Inland Empire, as shown in Figure 5-1. The existing warehouse also appears to be located in the cluster of the agencies. 


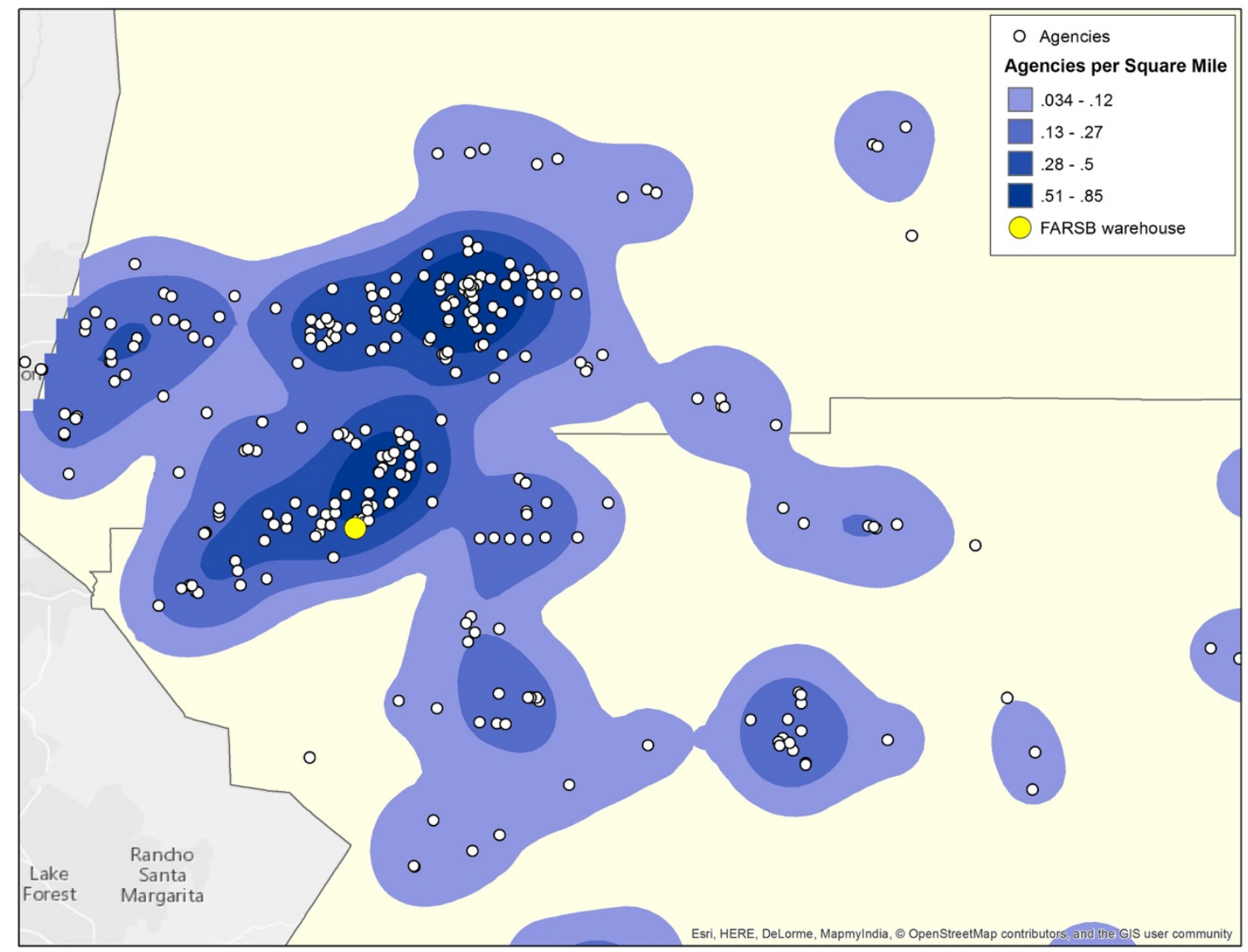

Figure 5-1: The spatial distribution of the agencies and the warehouse.

To further quantify the spatial relationship between the warehouse and agencies, a service area analysis was conducted. A network feature dataset was created from the Streets feature class and a 30-minute service area around the warehouse was generated with the Service Area Analysis tool in ArcGIS (Figure 5-2). Once the service area was created with 30-minute drive time limit, the served and underserved agencies by the warehouse were identified. The warehouse was covering 203 out of $360(56.3 \%)$ agencies within 30 minutes' driving distance, while there were 157 underserved agencies. 


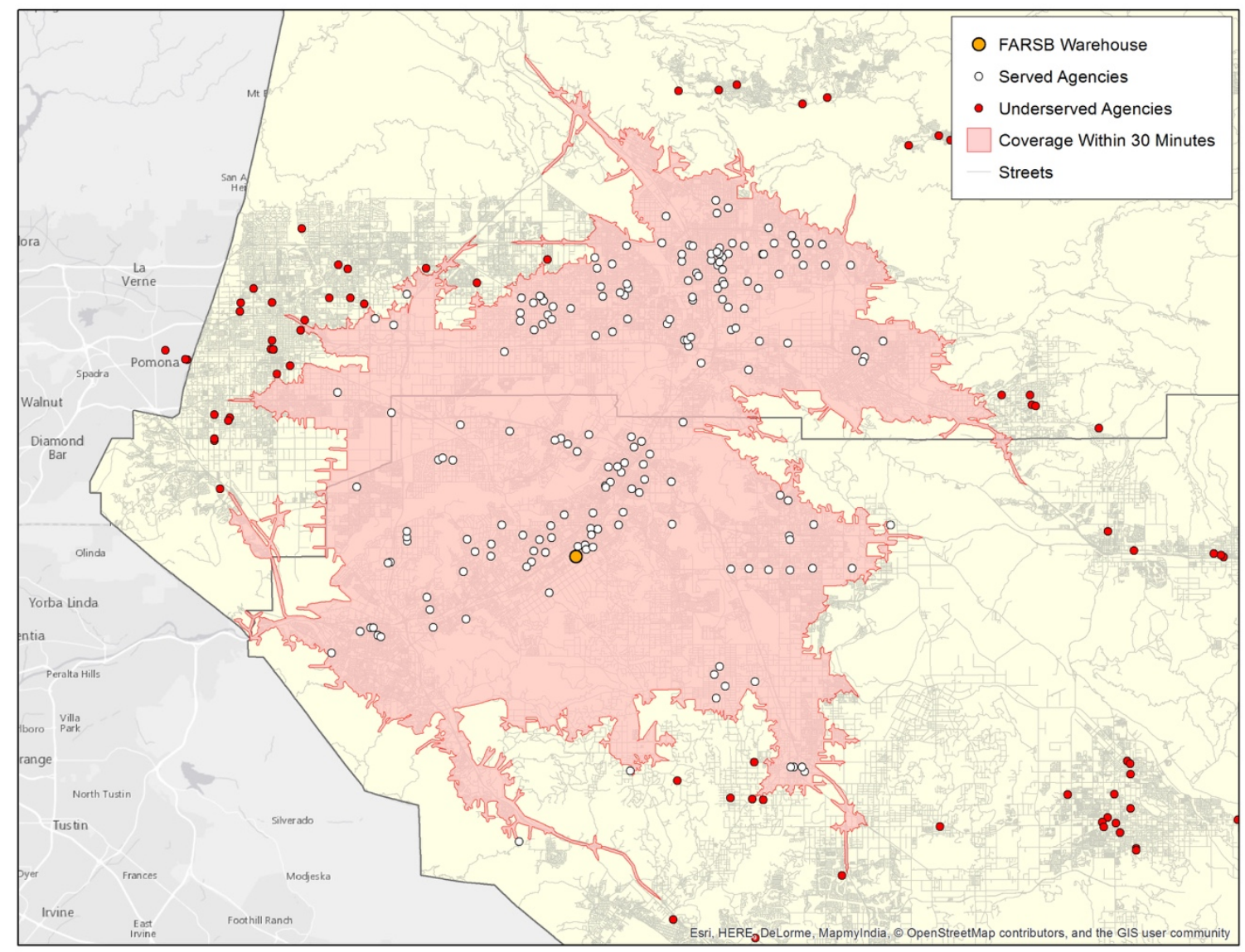

Figure 5-2: The service area within 30 minutes' drive from the warehouse.

The proposed new warehouse then should maximize the coverage for these underserved agencies with a 30-minute driving constraint.

\subsubsection{Selecting the Qualified Locations}

After the spatial proximity between the existing warehouse and agencies had been analyzed, the locations that met the client's criteria needed to be selected. Figure 5-3 illustrates the progress of the parcels layer for each criterion. 


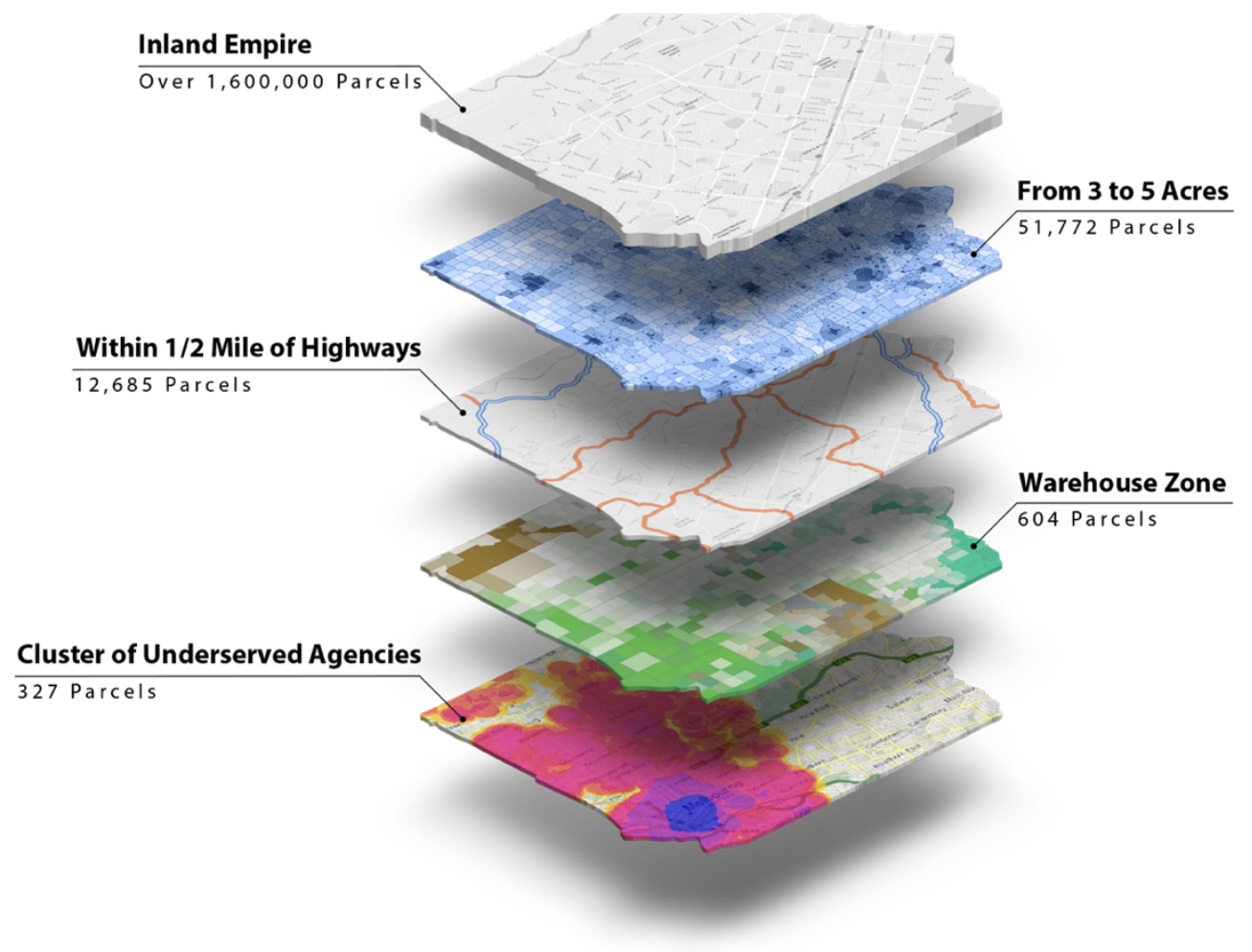

Figure 5-3: Selections process.

The Parcels feature class (polygons) was used in this phase as a basis to identify the parcels that matched all the criteria. Select By Attributes and Select By Location were the selection tools that were used in this phase of the analysis. There were over 1,600,000 parcels within the Inland Empire; however, that number started to diminish with each criterion. In the first place, 51,772 parcels were identified as having an area between three and five acres. In order to identify the areas that were within one-half mile of major highways, a half-mile buffer was created around highways that were selected from the Streets feature class. As a result, 12,685 qualifying parcels were identified within onehalf mile of major highways. Then the Land-Use feature class was used to identify 604 parcels that could be used for warehouses.

In order to meet the last criterion, which is about locating the warehouse in the cluster of the underserved agencies, the kernel density method was used to identify the concentrations of the underserved agencies. While the output of the Kernel Density tool was a raster, it was necessary for it to be converted into a vector feature class to complete the site selection phase. The density raster was then reclassified into two classes: high density and low density, with Natural Breaks (Jenks) classification method. The reclassified raster output was converted into a polygon feature class by using the Raster To Polygon tool, and the high density areas are displayed in Figure 5-4. 


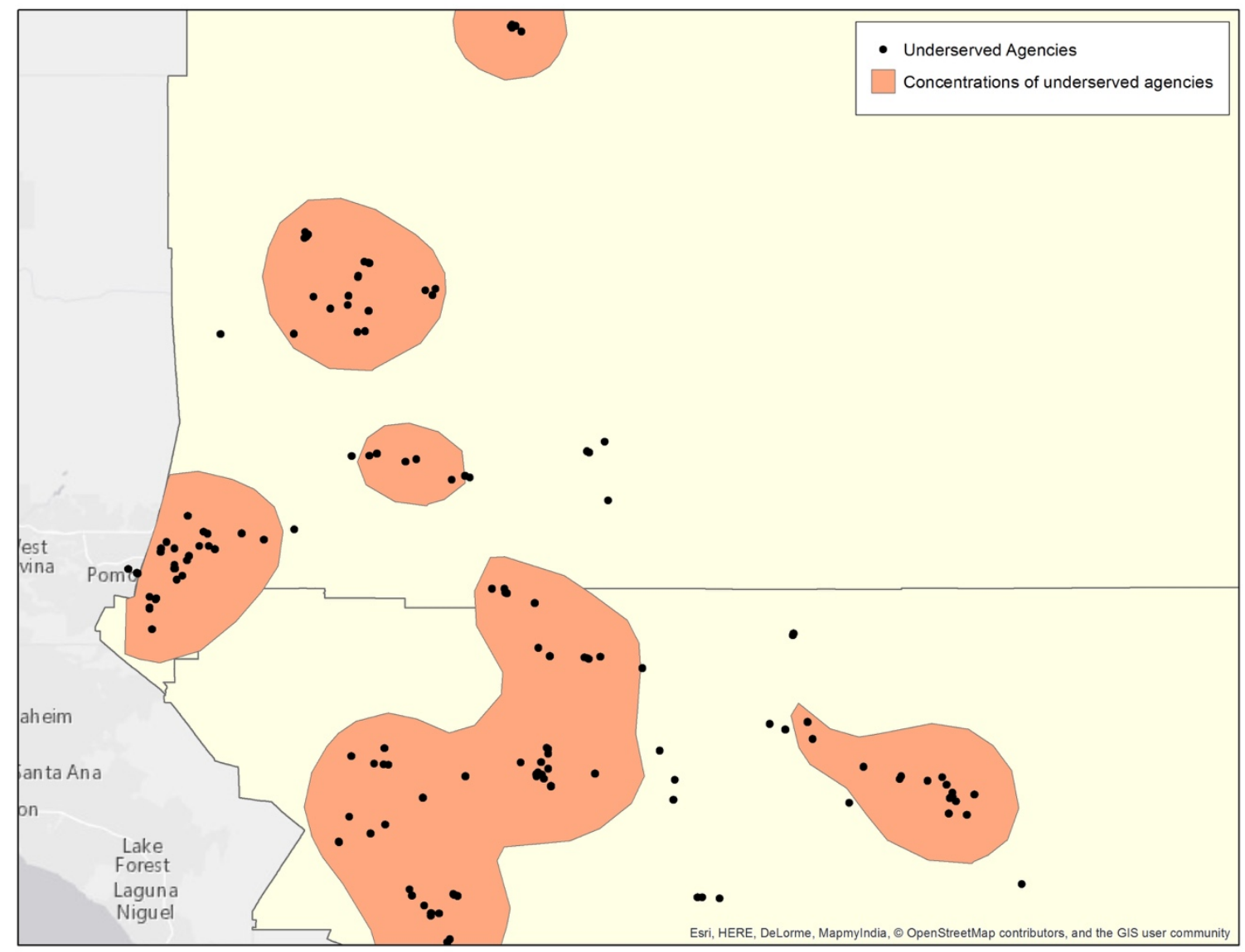

Figure 5-4: The concentrations of the underserved agencies.

After overlaying the areas where underserved agencies concentrated with the selected parcels from the previous steps, the sites were narrowed down from over $1,600,000$ parcels to 327 potential locations that met all the criteria.

\subsubsection{Location-Allocation Analysis}

Location-allocation analysis includes various models for solving a variety of siteselection problems on a network dataset. The Location-Allocation Analysis tool in ArcGIS contains a few models that address certain questions about optimal facility locations. In this project, two models were used. The first one, Minimize Facilities, is used to identify the minimal number of warehouses required to cover as many underserved agencies as possible with the 30-minute driving constraint. Using the warehouse locations yielded from this model as the candidate location, the Maximize Coverage model was applied to select the optimal location from the candidate locations that yields the maximum coverage for all underserved agencies. The analysis process is explained below.

Since the parcels that meet the client's criteria are polygon features, it was necessary converted them into points for use in the location-allocation analysis. For that purpose, the Feature To Point tool was used to do the conversion, and the parcels were represented as a point in the center of each parcel. Figure 5-5 shows all the parcels after the 
conversion. The converted feature class and the network dataset-which was created for the service area analysis - were used in running the Location-Allocation tool by using two different problem types that were provided by the tool: Minimize Facilities and Maximize Coverage.

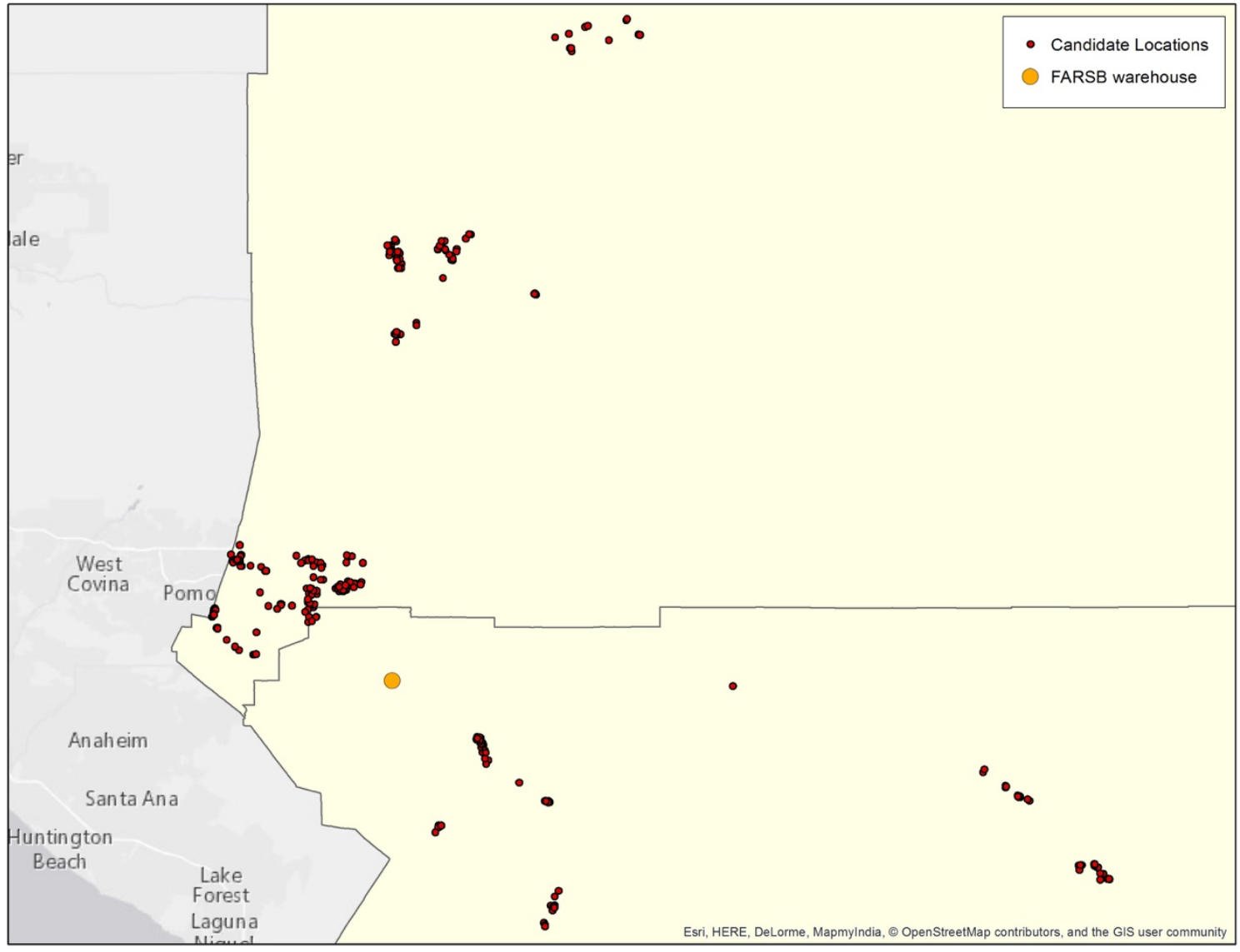

Figure 5-5: The parcels after the conversion to points.

The Minimize Facilities problem type within location-allocation analysis helps to determine the optimum minimum number of facilities that were maximizing coverage within a specific drive time. The tool has three different parameters: facilities, demand points, and impedance cutoff (time). In the facilities parameter, the existing warehouse was used as a required facility, while the 327 potential locations were used as candidates. In the demand points parameter, all 360 agencies were used as demands, and the impedance cutoff was 30 minutes from the facilities to the demands, as the client desired. After the tool was run, eight locations out of 327 were chosen as the optimum minimum facilities that were maximizing the coverage within 30 minutes' driving distance, as illustrated in Figure 5-6. The eight locations were more than was desired; therefore, it was necessary to use further analysis to identify the best location among them. Because Figure 5-6 shows elements that overlap, Figure 5-7 is included to show just the eight chosen locations for a better view. 


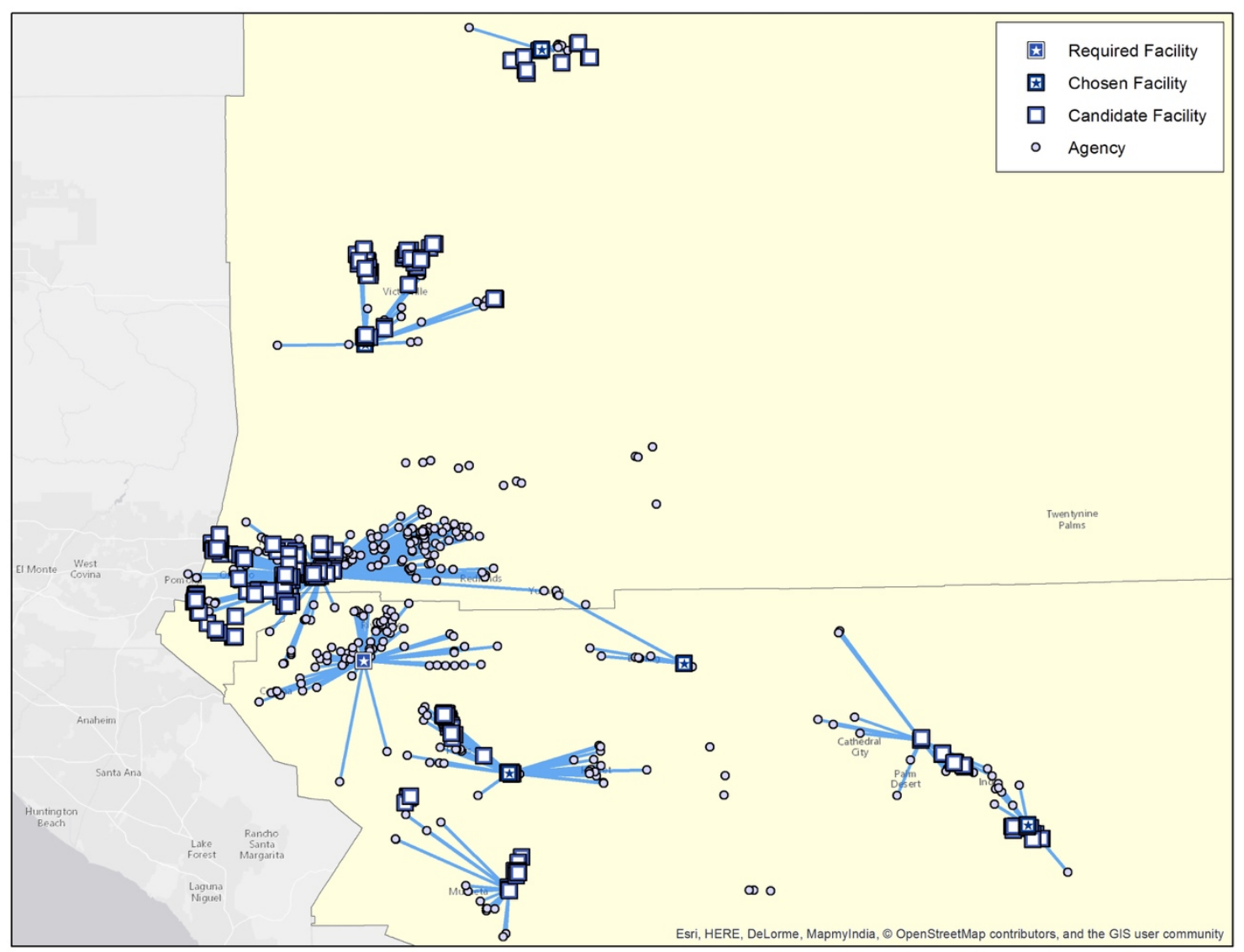

Figure 5-6: The Minimize Facilities problem type. 


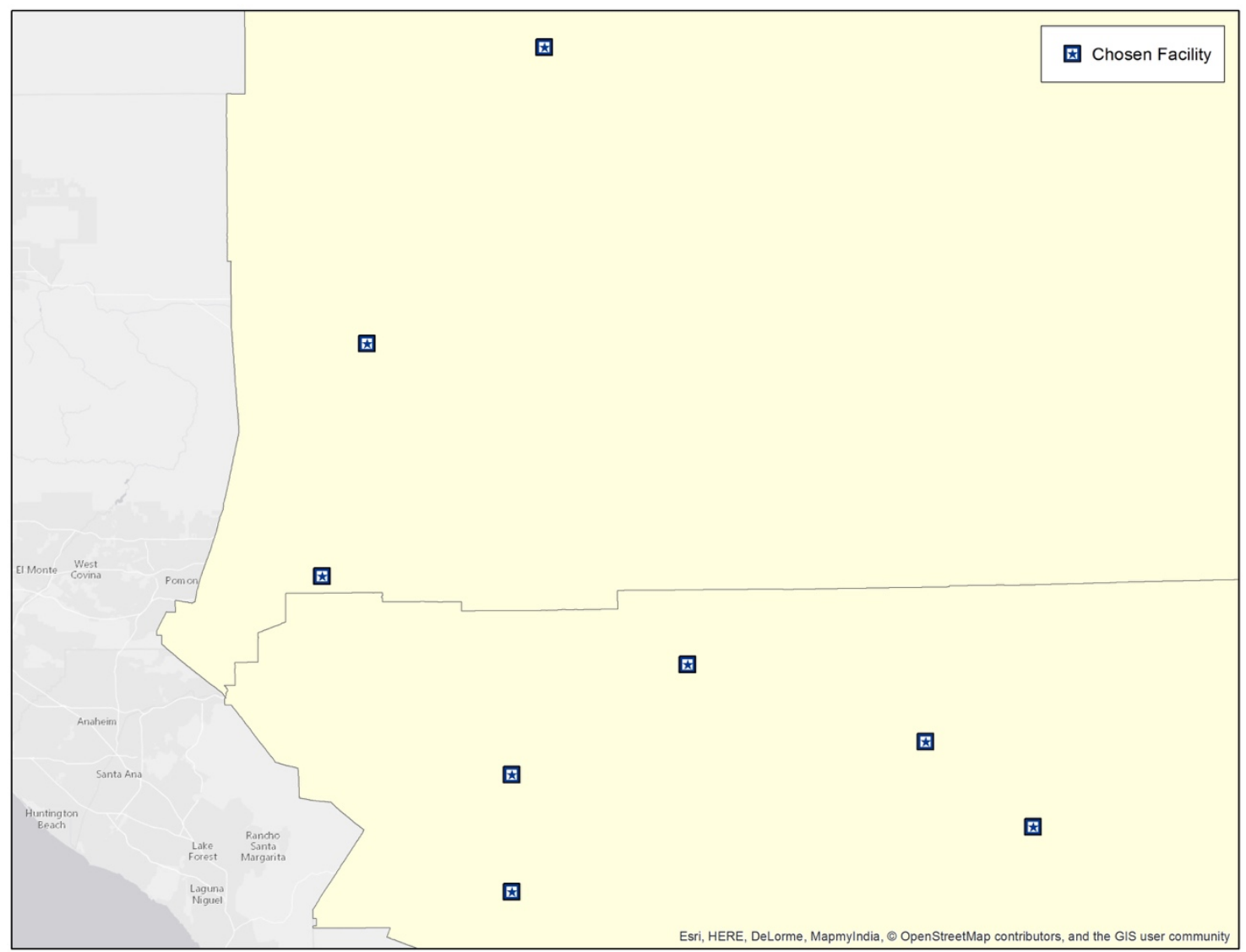

Figure 5-7: The chosen locations.

The Maximize Coverage problem type within location-allocation analysis helps to maximize the coverage within a specified drive time and number of facilities. Maximize Coverage has not only the same parameters as Minimize Facilities but also the quantity of facilities the user wishes to choose. In this case, the desired number was two facilities; one of them would be required and the other would be chosen. By the same token, the existing warehouse was used as a required facility; however, the candidates were the eight locations from the previous analysis's result. The 360 agencies were the demand points, and the impedance cutoff was 30 minutes' driving from the facilities to the demands. After the tool was run, one location out of eight was chosen as being the optimal site that would maximize coverage for the 360 agencies. 


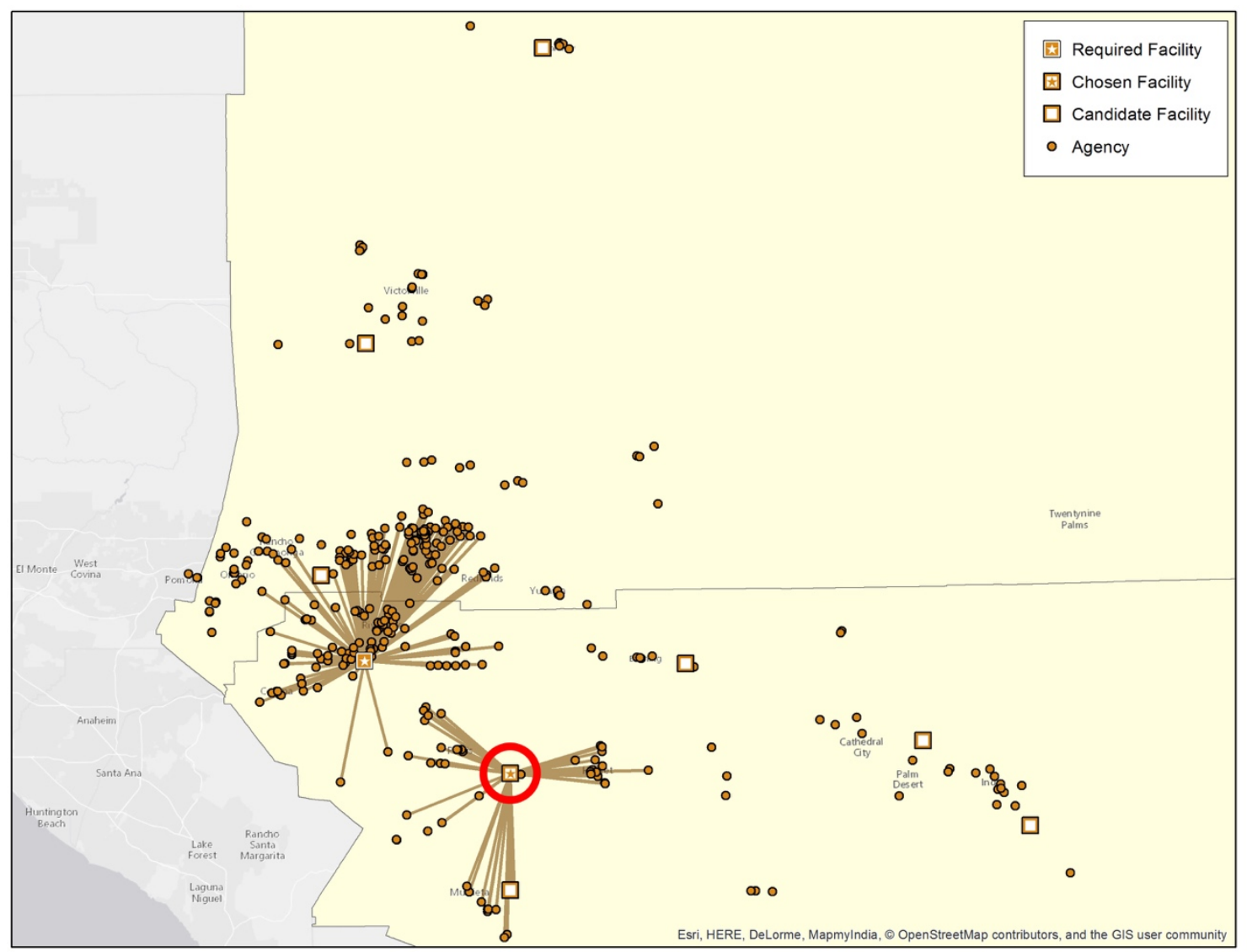

Figure 5-8: The Maximize Coverage problem type.

The new warehouse highlighted in the red circle in Figure 5-8 is located in Homeland city and close to State Highway 74. The impact of the new warehouse will be discussed in Chapter 6.

\subsection{Donors Story Map}

The client wanted to have a series of maps that represented some demographics about the Inland Empire to use in a public-awareness campaign and in direct-mail fundraising efforts. Creating a story map that included web maps was the ideal solution for this endeavor. As was mentioned in Chapter 4, the data source for this story map was the American Community Survey (ACS); however, it was derived from Esri ArcGIS Online. To create the story map, the web maps had to be created first. Two different web maps were created to be embedded in the story map: Poverty and Food Stamps, and Households Income.

\subsubsection{Poverty and Food Stamps Web Map}

The client wanted to have a map that represented the percentage of households with income below poverty level with an overlay of the percentage of households receiving food stamps/Supplemental Nutrition Assistance Program (SNAP) benefits, based on ZIP 
codes with an overlay of congressional district boundaries. To create this kind of map, using a multiscale bivariate choropleth map was the best solution. A bivariate choropleth map shows the correlation among two variables on a single map by merging two different sets of colors.

ZIP Codes and Congressional Districts feature layers were used in this web map; the layers were enriched by the determined variables by using the Enrich Layer tool in ArcGIS Online. Because some of the boundaries extended beyond the study area, the client asked that they be clipped so that all the boundaries would be within the study area. However, the inability of ArcGIS Online to perform clipping or create the matrix legend of the bivariate choropleth map, it was necessary to migrate the feature layers to ArcGIS for Desktop. The enriched ZIP Codes and Congressional Districts feature layers as well as the Inland Empire boundary were transferred to ArcGIS for Desktop. The enriched feature layers were clipped by the Inland Empire boundary, so the result was having the ZIP Codes and Congressional Districts feature classes within the Inland Empire. Figure 5-9 illustrates the features before and after the clip. 


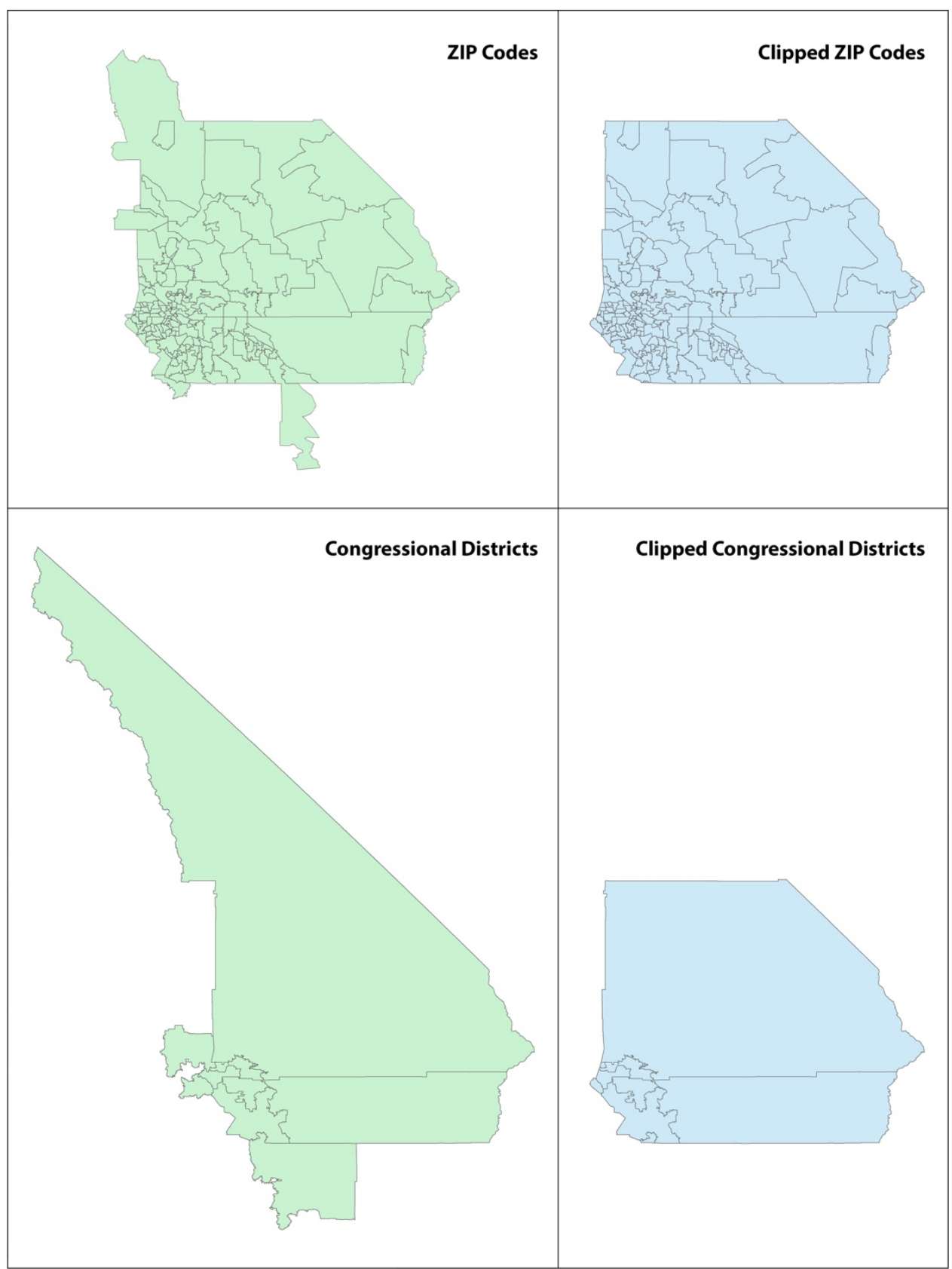

Figure 5-9: The feature classes before and after the clip.

In order to create a bivariate legend and symbolize the ZIP Codes feature class, it was important to create three new fields: Poverty Quantile, Food Stamps Quantile, and Bivariate Class. The last one should be calculated from the two other fields. Buckley (2015), Esri cartographer, developed a Python script that calculates a quantile class for each value of a field in a feature class. The reason of using quantile classification instead of other classification methods is that the quantile has values in each class, and that is very important for creating a bivariate map. Once the script was run, the two Poverty Quantile and Food Stamps Quantile fields were classified into three classes. After that, 
the Bivariate Class field was calculated to have nine classes based on the two classified fields, as shown in Table 5-1.

Table 5-1: Classified fields for the ZIP Codes feature class.

\begin{tabular}{|c|c|c|}
\hline Poverty Quantile & Food Stamps Quantile & Bivariate Class \\
\hline 1 & 1 & 1 \\
\hline 1 & 2 & 2 \\
\hline 1 & 3 & 3 \\
\hline 2 & 1 & 4 \\
\hline 2 & 2 & 5 \\
\hline 2 & 3 & 6 \\
\hline 3 & 1 & 7 \\
\hline 3 & 2 & 8 \\
\hline 3 & 3 & 9 \\
\hline
\end{tabular}

Not only the ZIP Codes feature class but also the Congressional Districts feature class had three classified fields; however, the quantiles were classified into two classes due to smaller number of polygon units contained in the congressional district level; the Bivariate Class had four classes, as shown in Table 5-2.

Table 5-2: Classified fields for the Congressional Districts feature class.

\begin{tabular}{|c|c|c|}
\hline Poverty Quantile & Food Stamps Quantile & Bivariate Class \\
\hline 1 & 1 & 1 \\
\hline 1 & 2 & 2 \\
\hline 2 & 1 & 3 \\
\hline 2 & 2 & 4 \\
\hline
\end{tabular}

Buckley also developed color schemes for bivariate maps, and one of those schemes was used to design the map and legend based on the Bivariate Class. Figure 5-10 illustrates the color scheme of the ZIP codes and congressional districts legends, and each color has its own bivariate class.

Zip Codes Legend

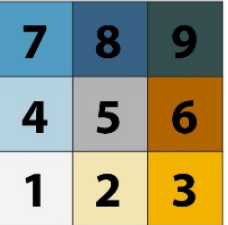

Districts Legend

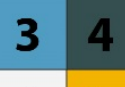

12

Figure 5-10: Bivariate legends. 
Due to the limitation of ArcGIS Online to display the two customized legends for two scale levels dynamically, the solution was to display the legends in pop-up windows. Each bivariate class in the both of the geographic units-ZIP codes and congressional districts - had a particular legend heavily outlined in black (other colors are possible), as shown in Figure 5-11.

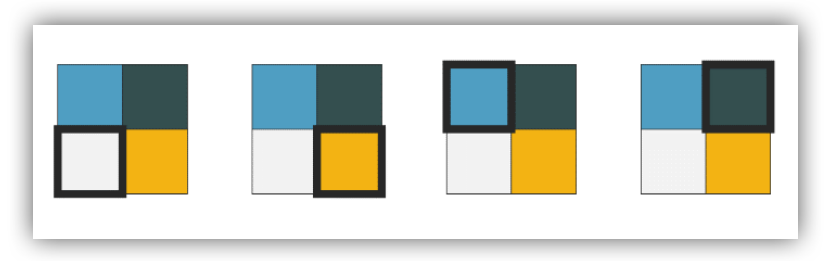

Figure 5-11: The congressional districts outlined legends.

Thirteen legends were created in a PNG image format and uploaded into online storage. Two CSV tables were created by Microsoft Excel; one of them included nine URLs of the ZIP codes legends, and the other included four URLs of the congressional districts legends. Then, the tables were joined to both feature classes by using ArcGIS for Desktop to gets new fields for the pop-up legends. Consequently, the ZIP Codes and Congressional Districts feature layers had four new fields: Poverty Quantile, Food Stamps Quantile, Bivariate Class, and Pop-up Legend, as illustrated in Figure 5-12. Ultimately, both feature classes were published to ArcGIS Online as feature services.

\begin{tabular}{|c|c|c|c|}
\hline \multicolumn{2}{|l|}{ Table } & & $\square \times$ \\
\hline \multicolumn{4}{|c|}{ 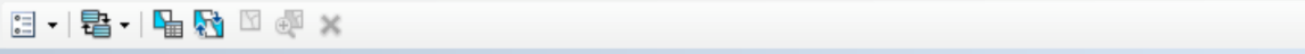 } \\
\hline \multicolumn{3}{|c|}{ Congressional Districts } & $x$ \\
\hline Poverty Quantile & Food Stamps Quantile & Bivariate Class & $\begin{array}{l}\text { Popup_Legend } \\
\end{array}$ \\
\hline 1 & 1 & 1 & http://www.mediafire.com/convkey/d5dc/rzj05qclh1qfk0wzg.jpg \\
\hline 1 & 1 & 1 & http://www.mediafire.com/convkey/d5dc/rzj05qclh1qfk0wzg.jpg \\
\hline 1 & 1 & 1 & http://www.mediafire.com/convkey/d5dc/rzj05qclh1qfk0wzg.jpg \\
\hline 1 & 1 & 1 & http://www.mediafire.com/convkey/d5dc/rzj05qclh1qfk0wzg.jpg \\
\hline 1 & 2 & 2 & http://www.mediafire.com/convkey/c59b/u6adyf1av4l1 gmbzg.jpg \\
\hline 2 & 1 & 3 & http://www.mediafire.com/convkey/b1db/3do80a08y5q|187zg.jpg \\
\hline 2 & 2 & 4 & http://www.mediafire.com/convkey/3595/7m5fcwj4mlhshhfzg.jpg \\
\hline 2 & 2 & 4 & http://www.mediafire.com/convkey/3595/7m5fcwj4mlhshhfzg.jpg \\
\hline 2 & 2 & 4 & http://www.mediafire.com/convkey/3595/7m5fcwj4mlhshhfzg.jpg \\
\hline \multicolumn{3}{|l|}{$<$} & > > \\
\hline 144 & " 圆国 ( 0 out of 9 & Selected) & \\
\hline \multicolumn{4}{|c|}{ Congressional Districts } \\
\hline
\end{tabular}

\section{Figure 5-12: The new fields of the Congressional Districts feature class.}

In ArcGIS Online, a new web map was created, and the feature services were included in that map as layers. The two layers - ZIP Codes and Congressional Districtswere displayed at different scales. The visibility range of the ZIP Codes layer was from County to Room, while the range of the Congressional Districts layer was from World to County. This process helped to display the data of two different geographic units within a single web map; when end users zoom in, the districts polygons will be hidden and the ZIP codes will appear, and vice versa. 
An unexpected technical issue showed up; when zooming to make the ZIP codes range visible, the ZIP Codes layer did not display. That was because the ZIP Codes layer has many polygons, and the server was not responding appropriately to load and draw all of the polygons. After trying several different approaches to resolve this issue, a workaround was found within ArcGIS for Desktop. The solution was to split the ZIP Codes layer into two layers to reduce display time.

\subsubsection{Households Income Web Map}

The client desired to have another map that represented the percentage of households with an income $\$ 50,000$ and above based on ZIP codes. Using the same approach that was used for the previous web map, the feature layer was migrated from ArcGIS Online to ArcGIS for Desktop to be clipped by the Inland Empire boundary. Due to the unexpected technical issue that had occurred with the previous map, the same solution was used. Therefore, after clipping and splitting the feature in ArcGIS for Desktop, the feature layer was published as a feature service to ArcGIS Online. Brewer (2005) offered a series of color schemes for thematic mapping. Green usually represents financial information, so the Five-Class Specifications of bluish green (BuGn)-illustrated in Figure 5-14-were used to design this map. In the end, the pop-up windows for the ZIP Codes layers were configured for use in the story map.

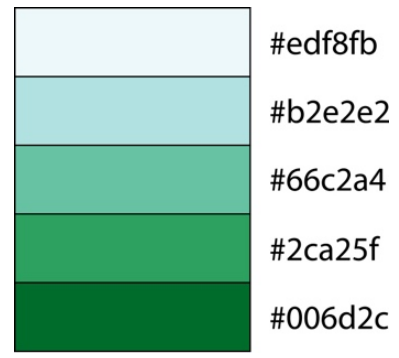

Figure 5-13: The BuGn color scheme.

\subsubsection{Story Map Series}

Ersi provided a variety of templates to use for web applications and story maps. The client reviewed all the templates and chose one of them to include the two previous maps. The Esri Story Map Series template was the selected one. The organization's website URL and logo were embedded into the story map. The two web maps were included, and each was on a separate tab with some narrative information about them.

\subsection{Agencies Story Map}

The client wanted to have another story map that would display the locations of the organization's agencies. The primary purpose of this story map would be to allow people in need to locate the agencies within their neighborhood and to know relevant information about each agency. The Agencies feature class was published as a feature service to ArcGIS Online. Once the feature service was published, a new web map was created and included that feature service as a layer. Pop-up windows for the Agencies 
layer were configured to display relevant information about each agency, such as its name, full address, phone number, group type, and operation hours.

There were 10 different group types of the agencies, and the client wanted to represent each of them with a unique symbol. Therefore, Adobe Illustrator CS6 was used to design 20 different icons for two scales; ten small icons for when user zooms out, and another 10 large icons for zooming in. Because the points in the map overlap and were concentrated at the small scale, displaying the icons with two scale levels helped enhance the visualization. Figure 5-15 illustrates the 20 icons with their group types based on the scale level of the web map. All the icons were saved as a PNG images and uploaded to online storage.

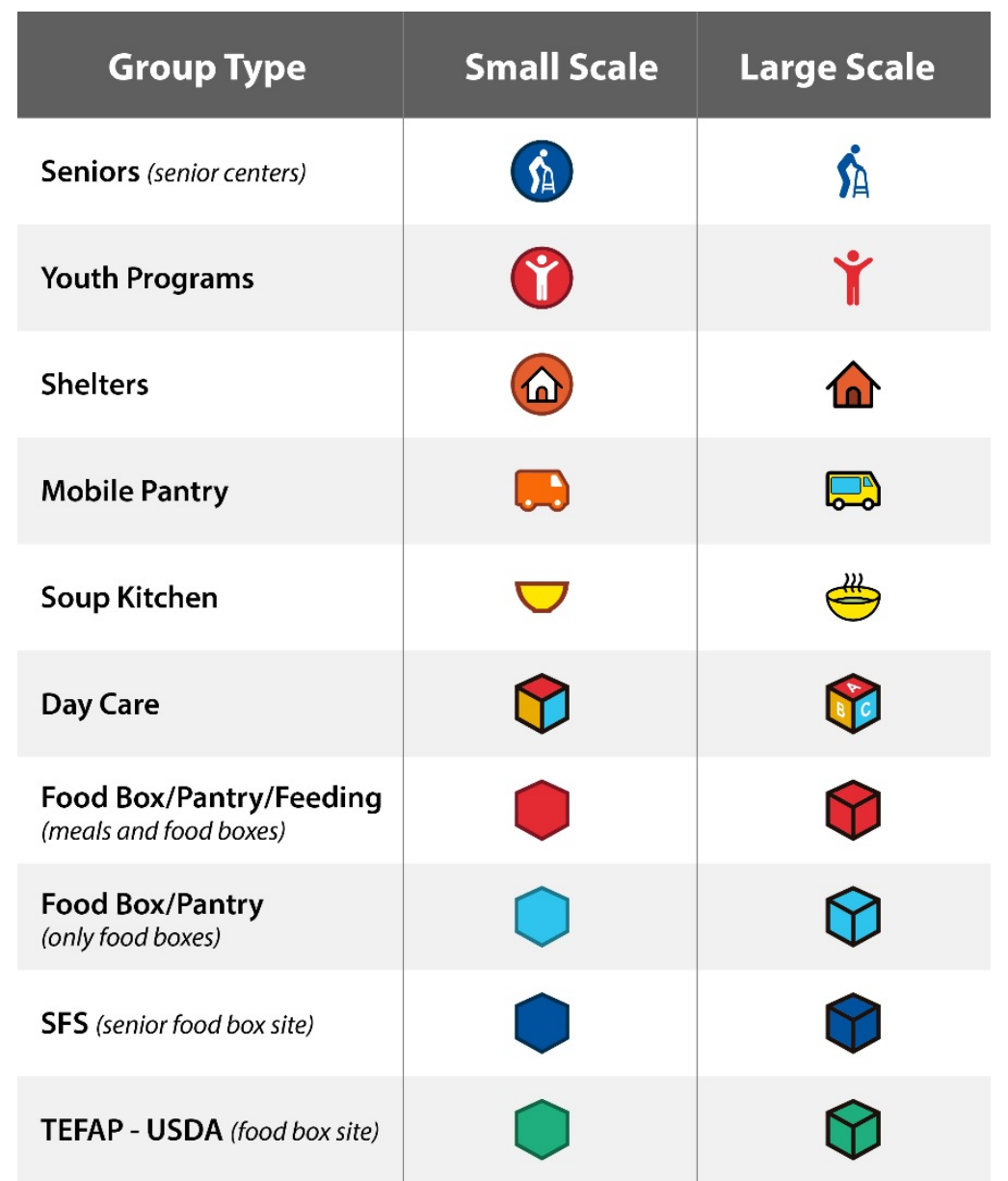

Figure 5-14: The icons of each group type and both scale levels.

The client wanted to have 10 layers based on the group types, so each layer included only the agencies of that layer's group type. This would help users hide and show the layers of agencies within a particular group. For that reason, the Agencies layer was duplicated to 20 layers based on the 10 group types so that each group had two layers for two scale levels. ArcGIS Online allows users to use custom images for points symbols; therefore, the symbols were configured by using the URLs of the designed icons. After that, the visibility of 10 layers was set up to range from Cities to Room, while the range of the other 10 layers was from World to Cities. As a result, when the user zooms in and 
out, the icons will change based on the scale level, as shown below in Figures 5-16 and 517.

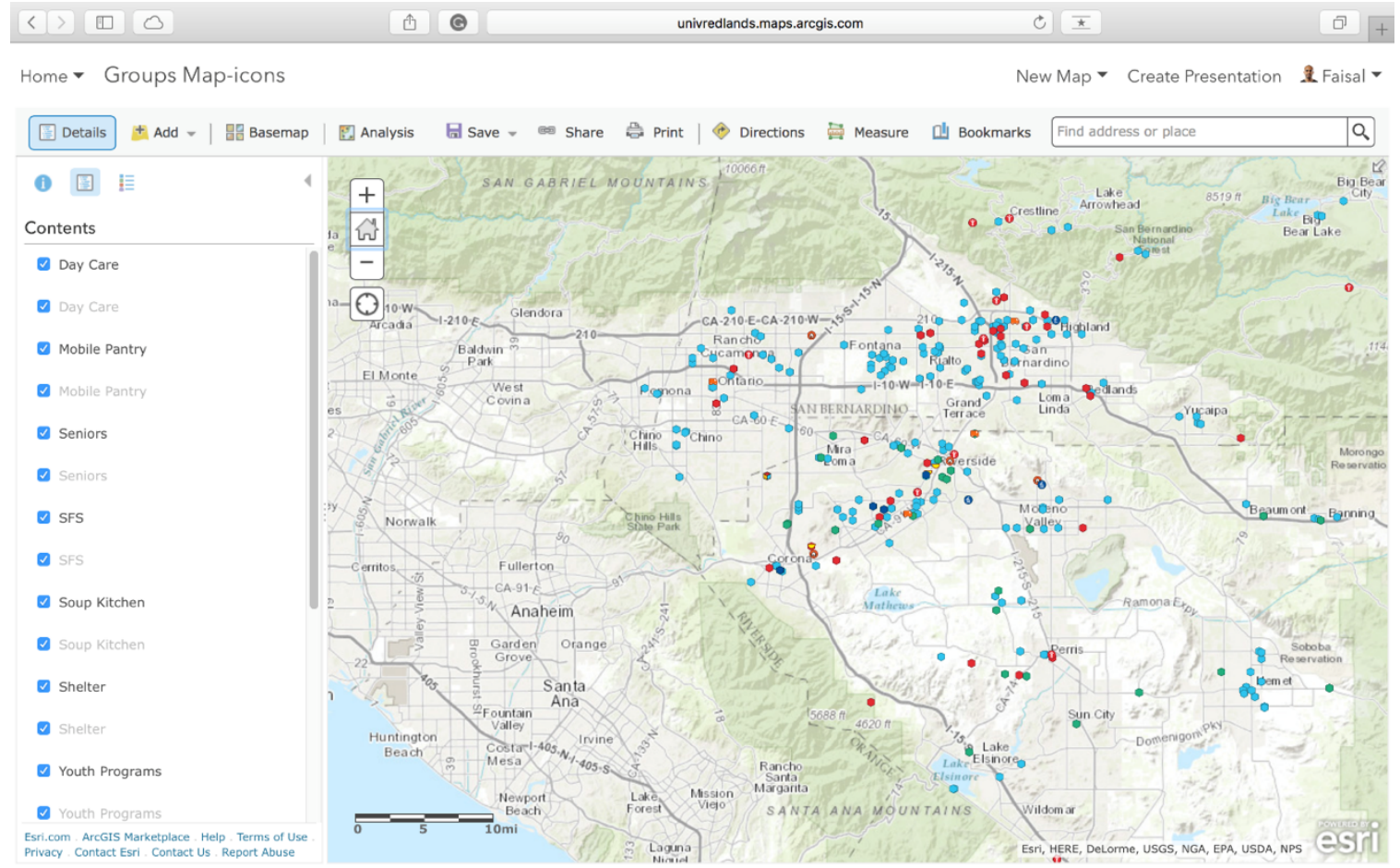

Figure 5-15: The web map showing agencies at the small scale level.

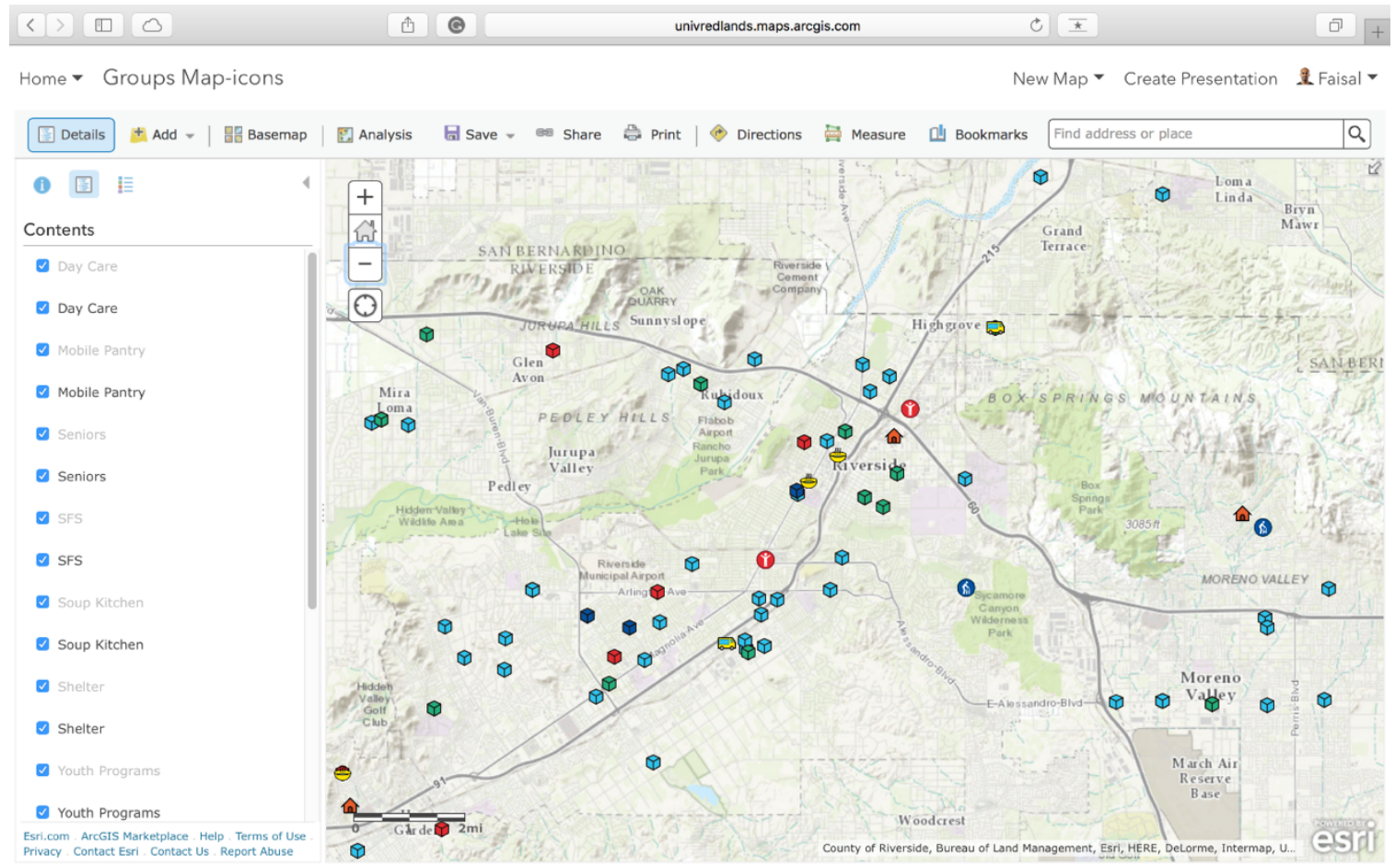

Figure 5-16: The web map showing agencies at the large scale level. 


\subsubsection{Basic Viewer Template}

The client chose the ArcGIS Basic Viewer template to display the agencies web map. The organization's logo and website URL were embedded into the title bar of the story map. Its search bar would allow users to find particular agencies on the map. The search bar was configured so that users could search by agency name, address, city, ZIP code, phone number, and group type. Moreover, the story map included a toolbar with a variety of tools that would help users interact with the map. The tools included Legend, Layers, Basemap Gallery, Details, Share, and Print.

\subsection{Summary}

This chapter discussed a variety of methodologies that were used to create diverse information products. Section 5.1 explained series of analyses that identified the optimal location for a new center for food delivery. Section 5.2 discussed the donors story map's creation at length due to the complexity of creating a multiscale and bivariate map for ArcGIS Online. Section 5.3 discussed the methodology of creating the agencies story map with its customized symbols. While this chapter has covered the methodologies, the following chapter will discuss the results. 



\section{Chapter 6 - Results and Analysis}

This chapter discusses the results and analysis of the implementations. The final outputs of this project were a file geodatabase including the final results of the analysis, and two story maps. Section 6.1 discusses the final results of the analysis and how they will impact the efficiency of Feeding America Riverside | San Bernardino (FARSB). Section 6.2 is about the donors' story map and its contents; it describes how the FARSB would take advantage of that story map. Section 6.3 discusses the agencies story map and the functionality that allows end users to interact with it. A summary of the chapter is provided in Section 6.4.

\subsection{Analyzing Optimal Locations}

One of the primary purposes of this project was to identify the optimal site for a second warehouse for FARSB in order to expand distribution so that everyone would have access to healthy and affordable food in the Inland Empire. The process of this siteselection analysis was described in Chapter 5. Out of 360 agencies the existing warehouse was covering, 203 (56.3\%) were within 30 minutes driving distance, while the remaining 157 were underserved agencies.

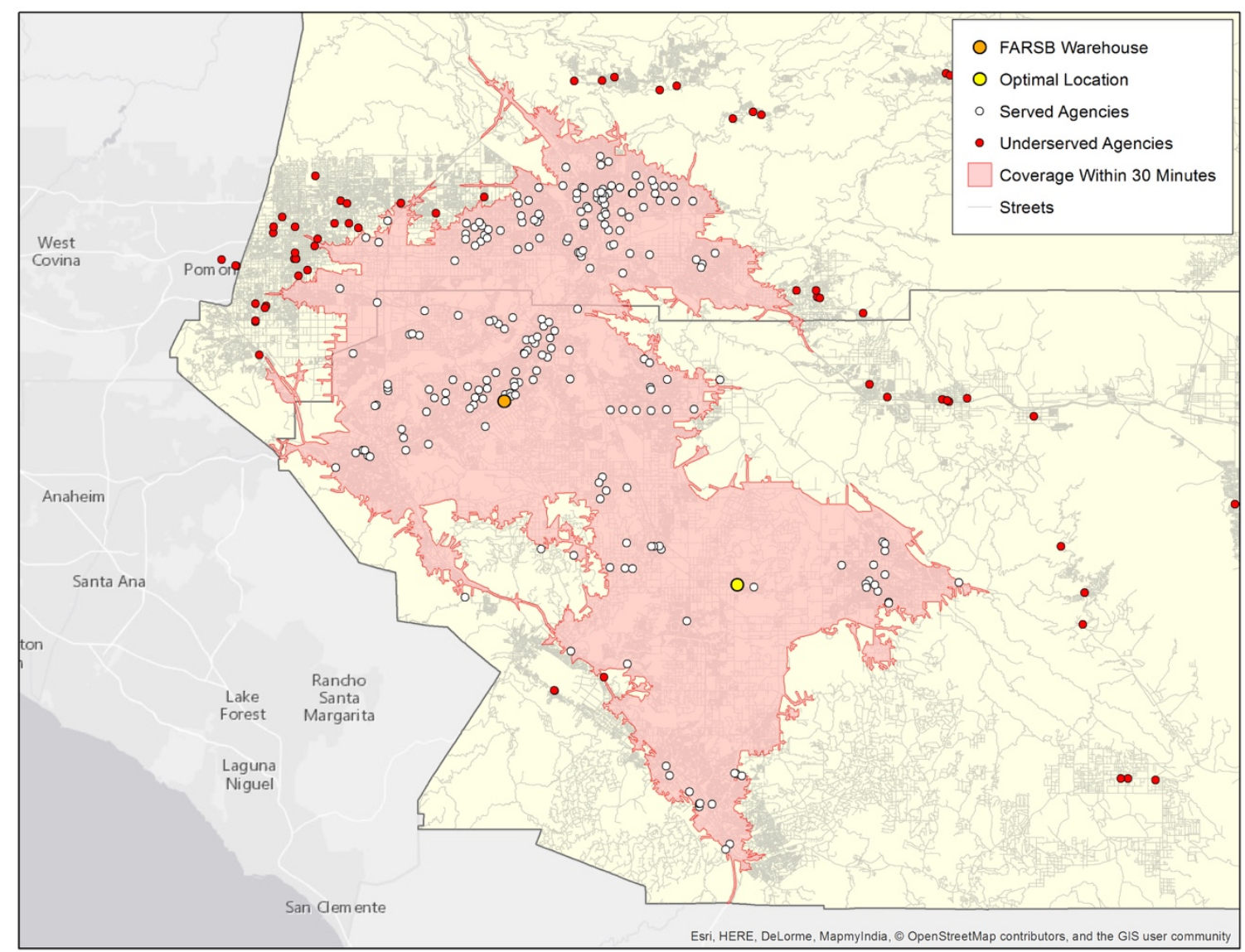

Figure 6-1: The coverage of FARSB warehouse including the proposed location within a 30-minute drive time. 
After a series of analyses were executed, the optimal location for a second warehouse was identified. If the organization and decision-makers decides to put the new warehouse in the proposed location, that will help to increase the distribution to 244 $(67.8 \%)$ of the agencies within 30 minutes, instead of 203 agencies. Moreover, that would relieve pressure on the existing warehouse. Within a 30-minute drive time, the existing warehouse would be reaching 194 agencies rather than 203, and the new warehouse would serve 50 agencies. The total coverage would expand by $11.5 \%$ - from $56.3 \%$ to $67.8 \%$ - and 41 more agencies would be covered within a 30 -minute drive time.

\subsection{Donors Story Map}

The main goal of this story map was to strengthen the foundation and corporate grants as well as government funding opportunities. Moreover, the client would use this story map in a public-awareness campaign and in the organization's direct mail fundraising efforts. The previous chapter described the process of creating this story map. The main interface of the story map is illustrated in Figure 6-2. The header contained the title, a link to the FARSB website, sharing options, the organization's logo, and a tab for each of the two web maps: Poverty and Food Stamps, and Households Income.

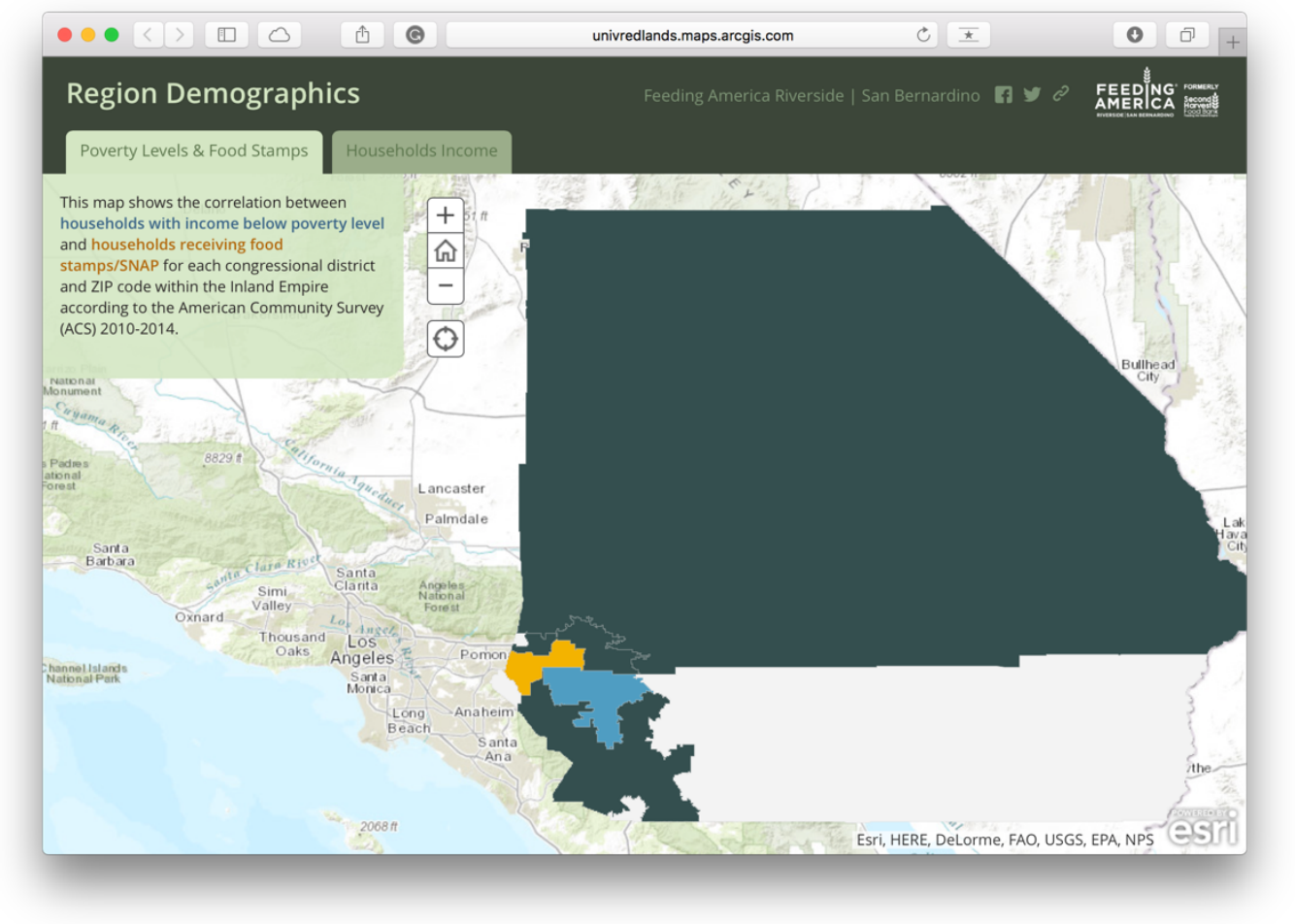

Figure 6-2: The interface of the donors story map.

The Poverty and Food Stamps map has narrative information on the left side, and the map is represented at the congressional districts level by default. When the user clicks on any polygon, a pop-up window will display relevant information about that polygon, as shown in Figure 6-3. (The figures in this chapter have been modified from their actual appearance on screen in order to show all of the contents of the pop-up boxes.) 


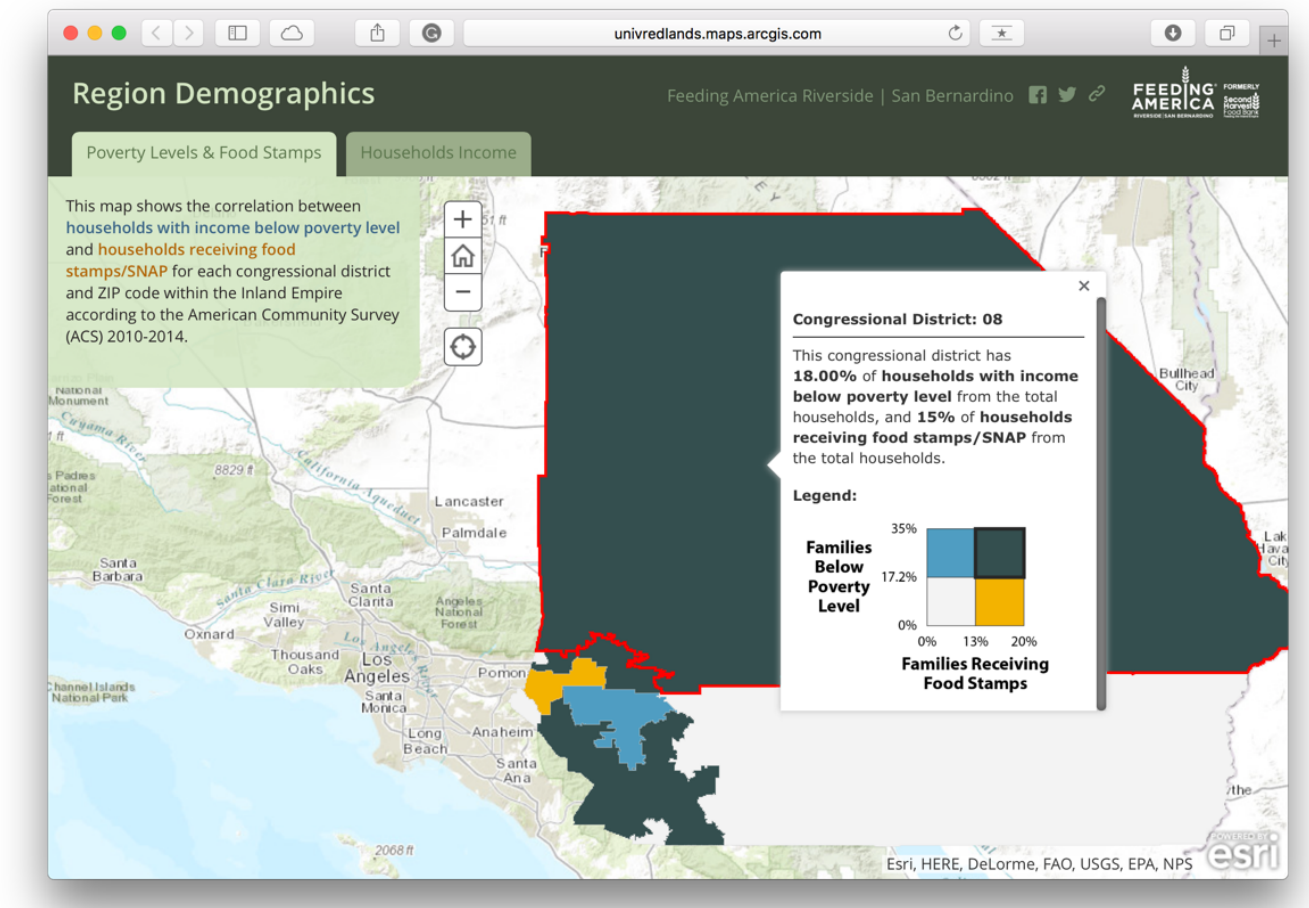

Figure 6-3: The pop-up window of congressional district 8.

The pop-up window includes the district number, narrative information about the percentage of poverty and food stamp recipients in that district, and a matrix legend that represents the correlation between the percentages of poverty and food stamp recipients in a graph. With the pop-up windows, end users would be able to read and understand the map from either the text or the legend. For instance, congressional district number 8 - the largest dark polygon (Figure 6-3) - had 18\% of households living below poverty level and $15 \%$ of households receiving food stamps. Another way to read that information is by using the legend to interpret the map itself; the district had high poverty, based on the overall poverty range, and a high number of food stamp recipients, based on the overall food stamps range.

The Poverty and Food Stamps map is a multiscale map; therefore, once end users zoom in to a particular scale level, the geographic unit will change from districts to ZIP codes, and vice versa when zooming out. For another example from this map, the south part of Indio had high poverty and a high number of food stamp recipients, as illustrated in Figure 6-4, while the north side of Indio had much lower poverty and fewer food stamp recipients, as shown in Figure 6-5. 


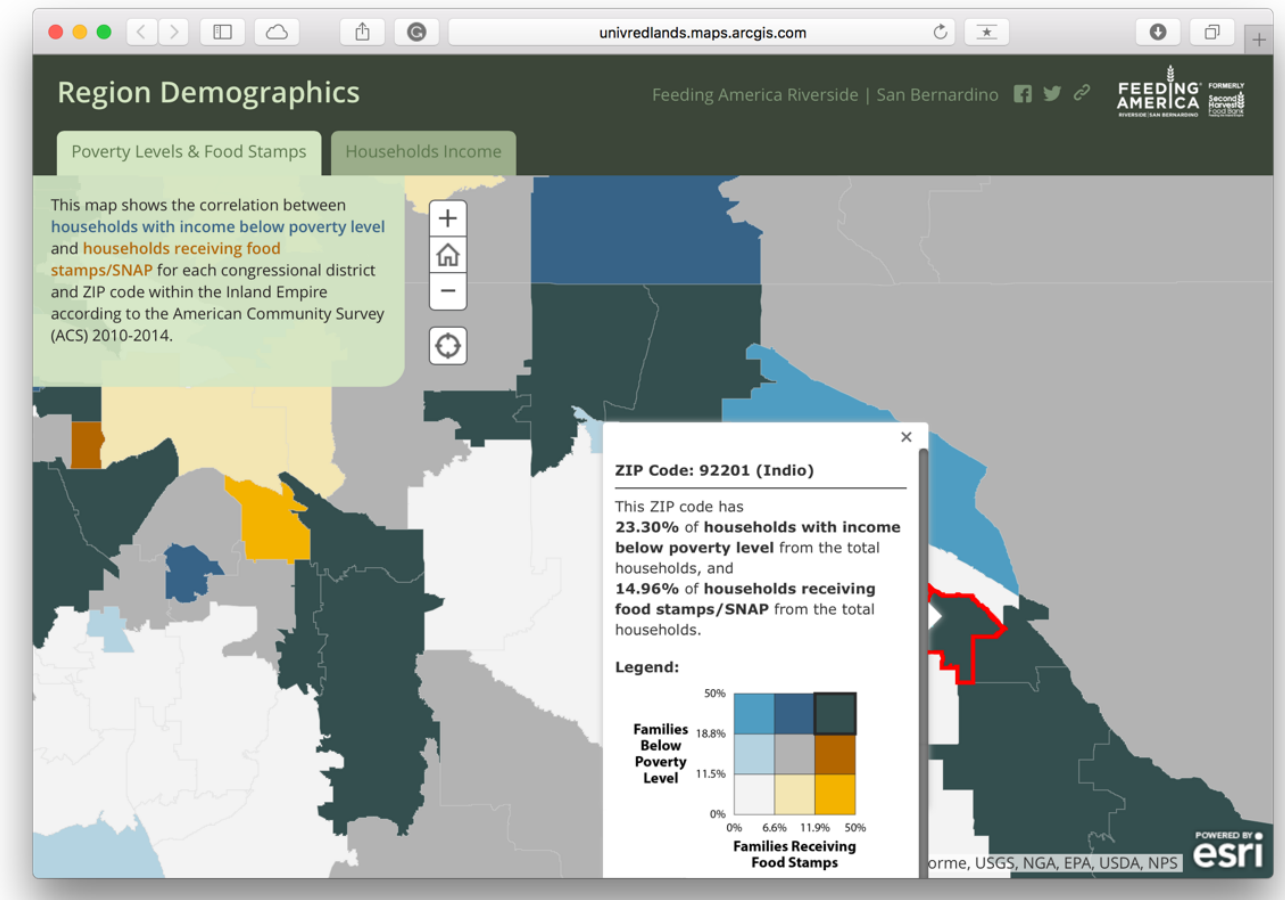

Figure 6-4: The south part of Indio.

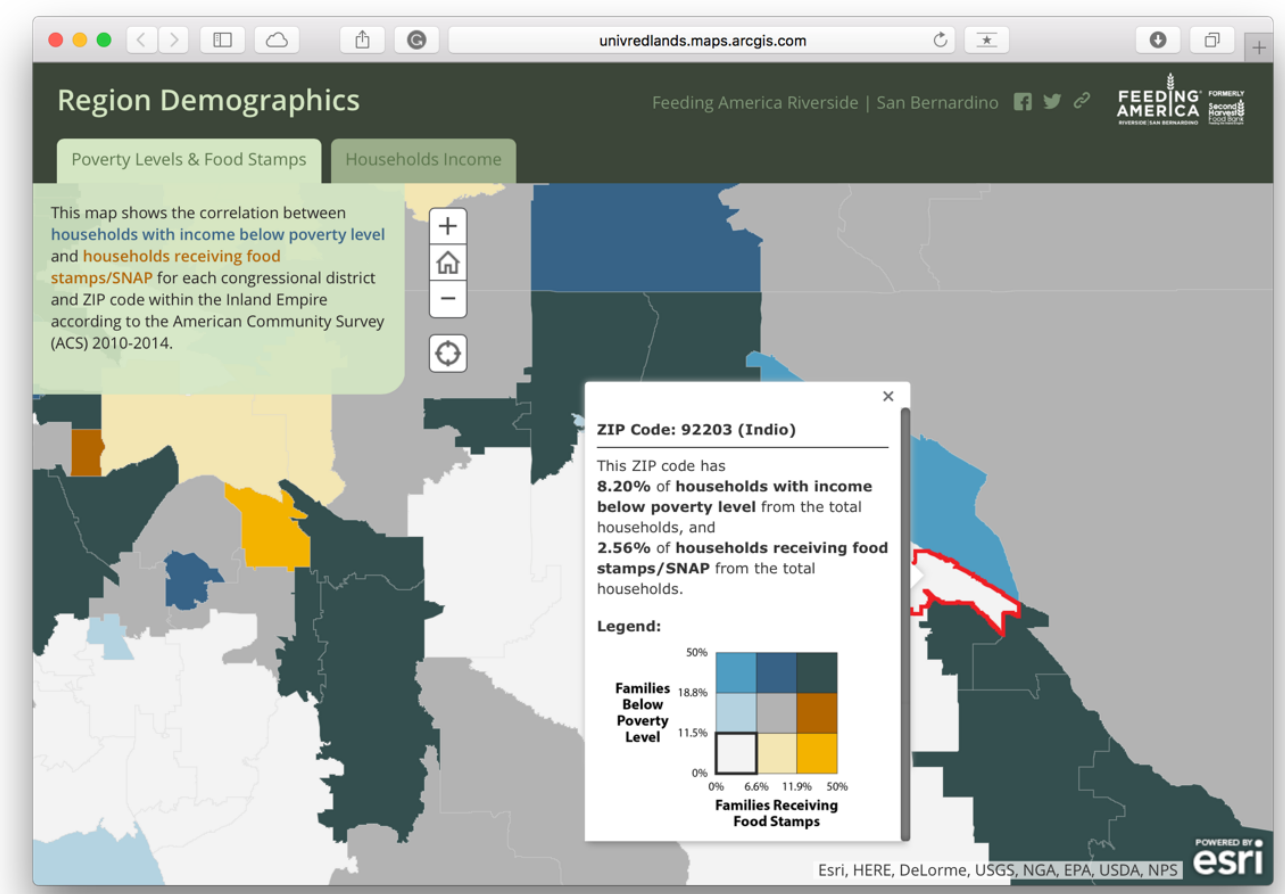

Figure 6-5: The north side of Indio. 
To take full advantage of this map, it would be very helpful for the FARSB to identify the areas of greatest need. The areas that have a high percentage of households below poverty level but a low percentage of households receiving food stamps would be considered a target, so the organization could focus on those areas to relieve poverty. Figure 6-6 illustrates one of the areas of greatest need.

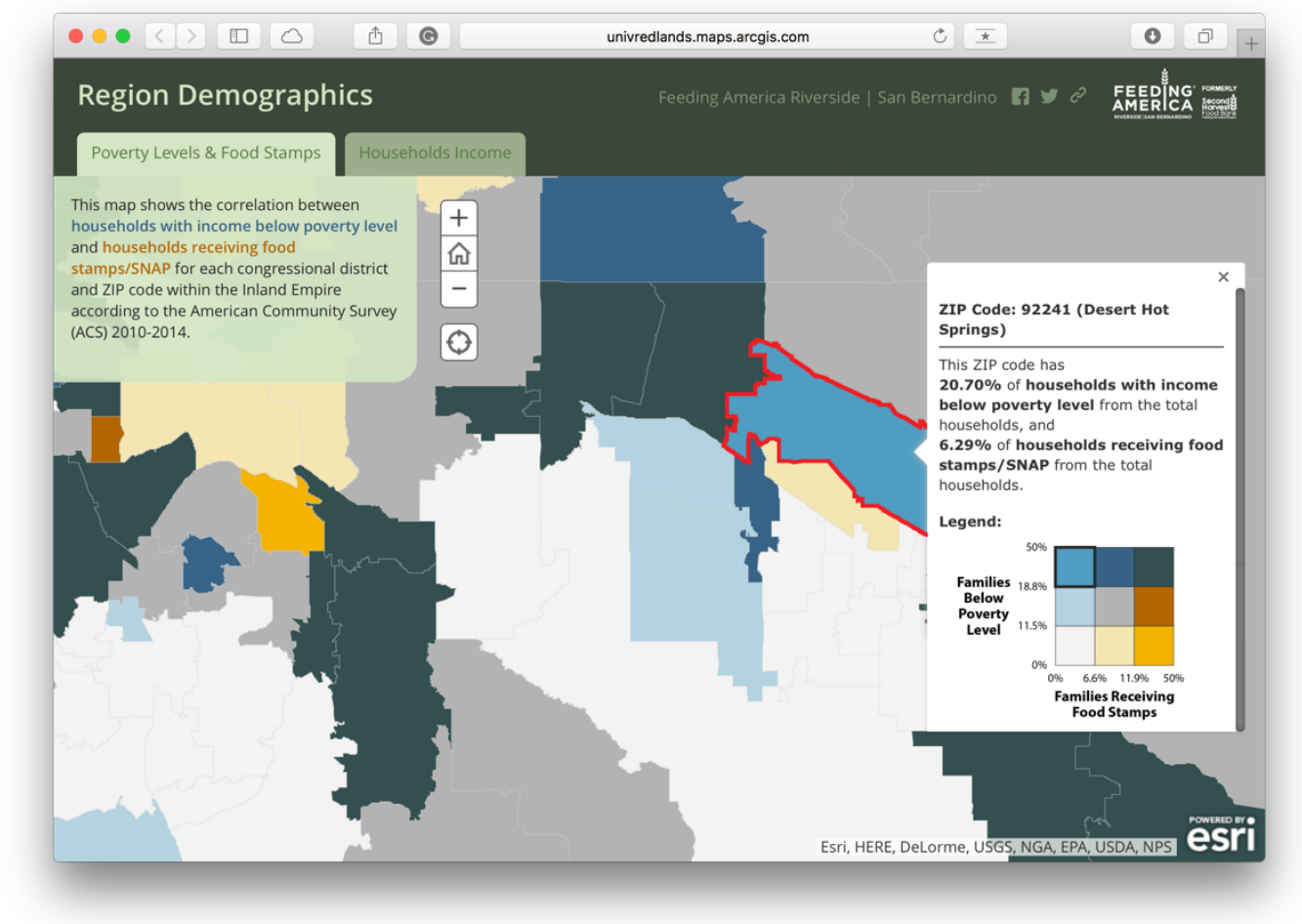

Figure 6-6: An example of the areas of greatest need.

When the end user clicks the Households Income tab, the contents of the story map changes to display the Households Income map. It has narrative information on the left side; it has a legend that explains how the colors on the map represent the percentage of households with an income of $\$ 50,000$ and above. The elements in the legend were organized in diminishing value of the percentages. Figure 6-7 shows the interface of the story map with the Households Income map activated. 


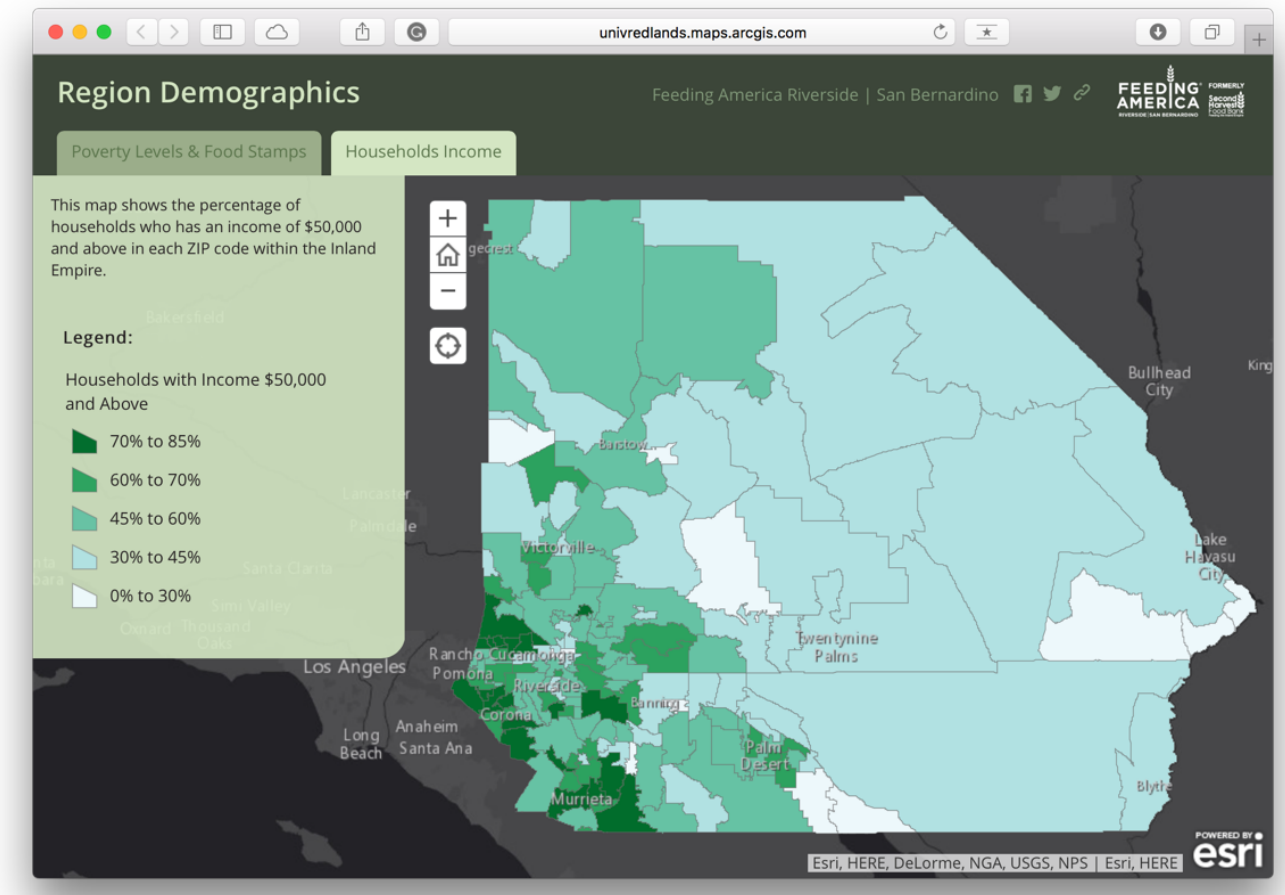

Figure 6-7: The interface of the donors story map while the Households Income map was activated.

When the end user clicks on any polygon, relevant information is displayed in a popup window, as shown in Figure 6-8. For instance, in Lake Arrowhead, 70.68\% of all households have an income of $\$ 50,000$ or above. This map could help the FARSB identify the areas that should be considered targets for increased efforts within the FARSB direct mail fundraising system. Also, the map could help the organization find potential donors in order to increase fundraising success. 


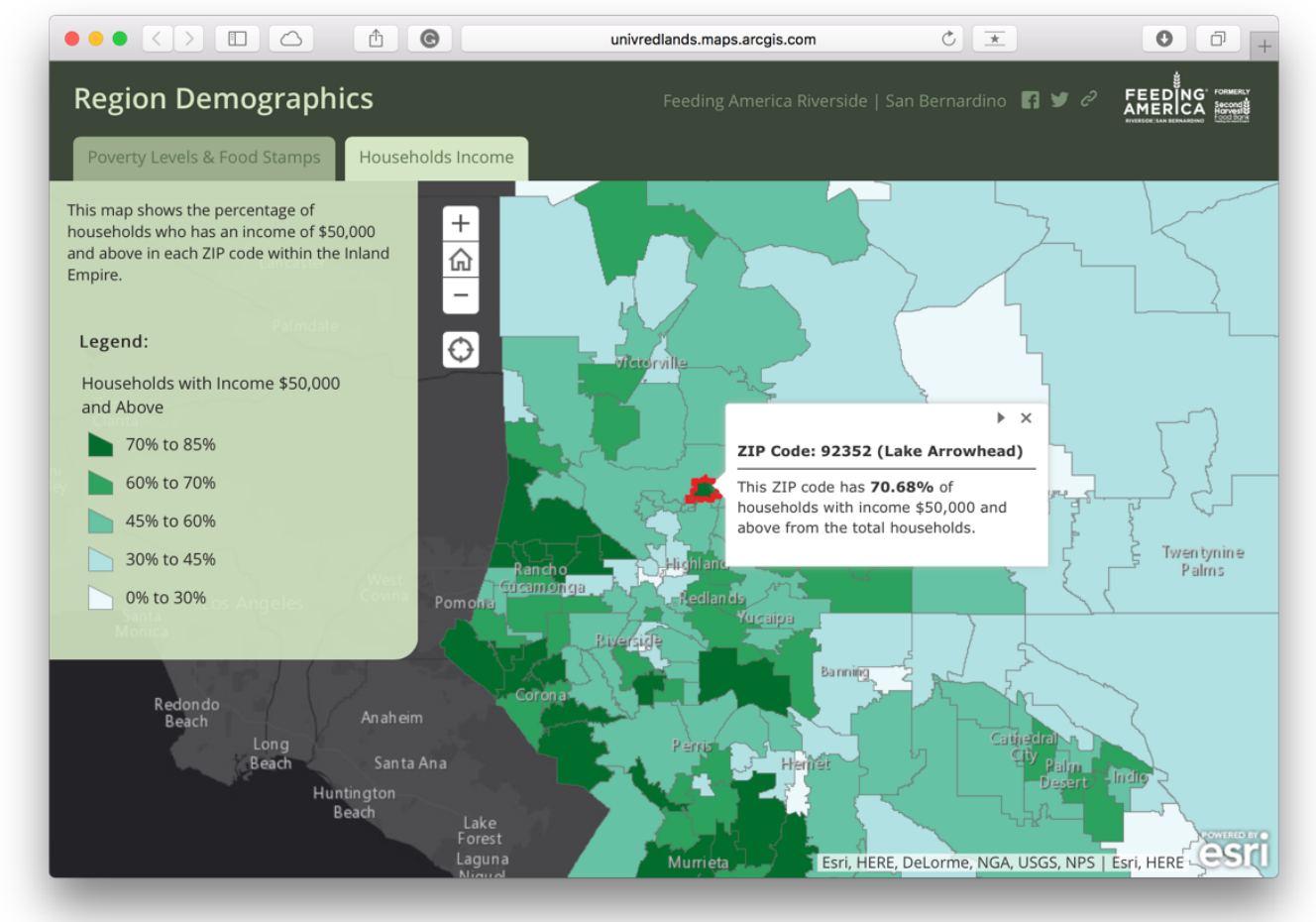

Figure 6-8: The pop-up window of the Lake Arrowhead area.

\subsection{Agencies Story Map}

The primary goal of this story map was to help people locate their neighborhood FARSB agencies. This story map included one interactive map; the end user can zoom in and out to locate the agencies. When the story map is launched, it is at a small scale, so the icons are miniscule; however, when the end user zooms in to a particular scale level, the icons become larger and include more details. Figures 6-9 and 6-10 illustrate the icons on the map at different scale levels. 


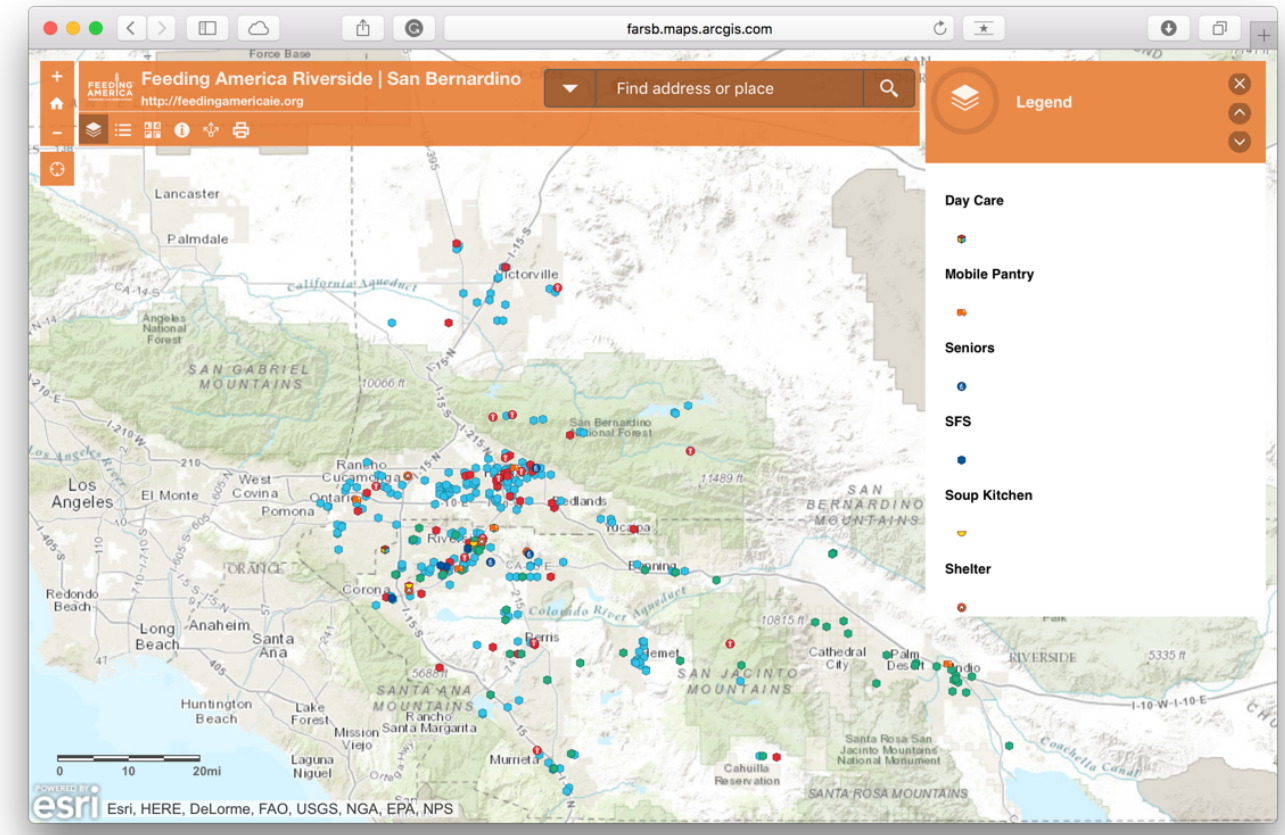

Figure 6-9: The icons on the map at a small scale level.

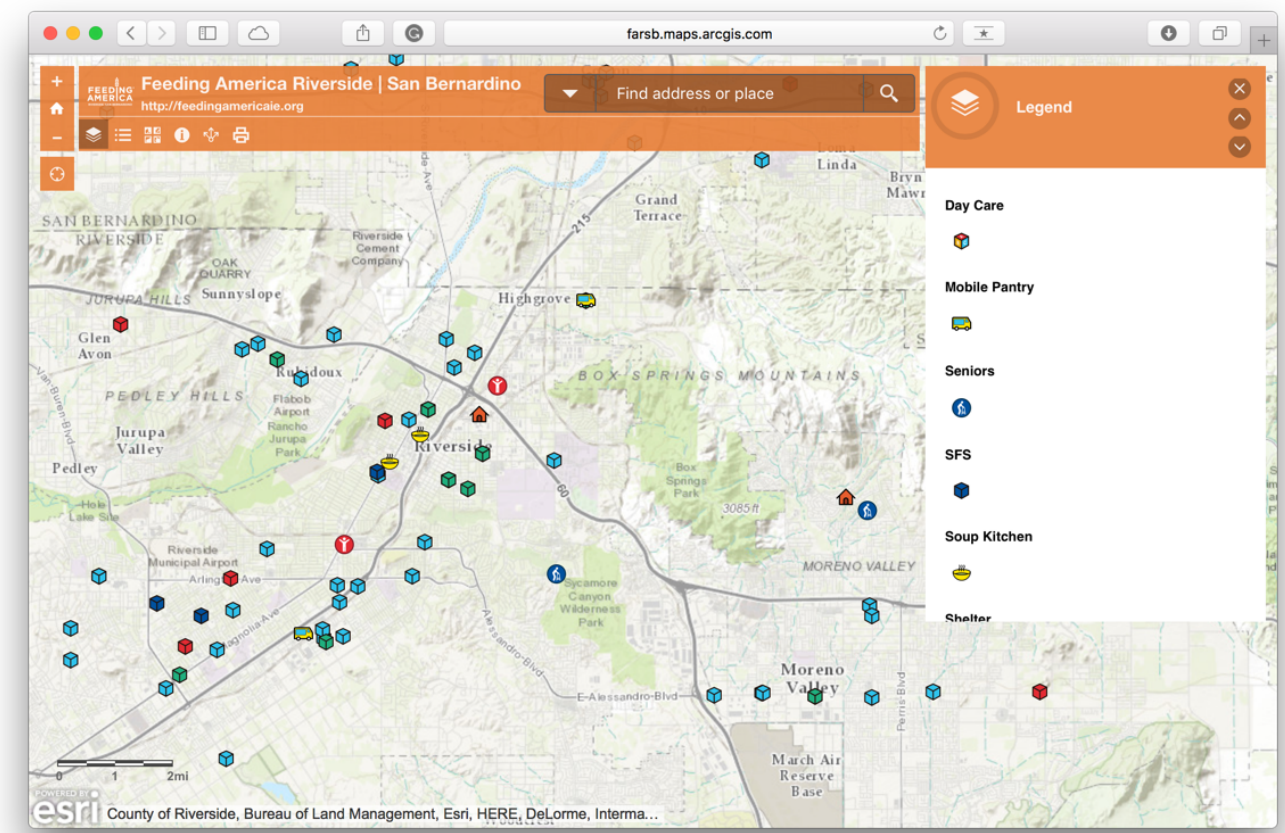

Figure 6-10: The icons on the map at a large scale level. 
Each point on the map has relevant information that shows up in a pop-up window when the user clicks on that point (Figure 6-11). The pop-up window includes information such as agency name, address, city, state, ZIP code, phone number, group type, weekday operation hours, and comments (e.g., whether an agency is closed on holidays).

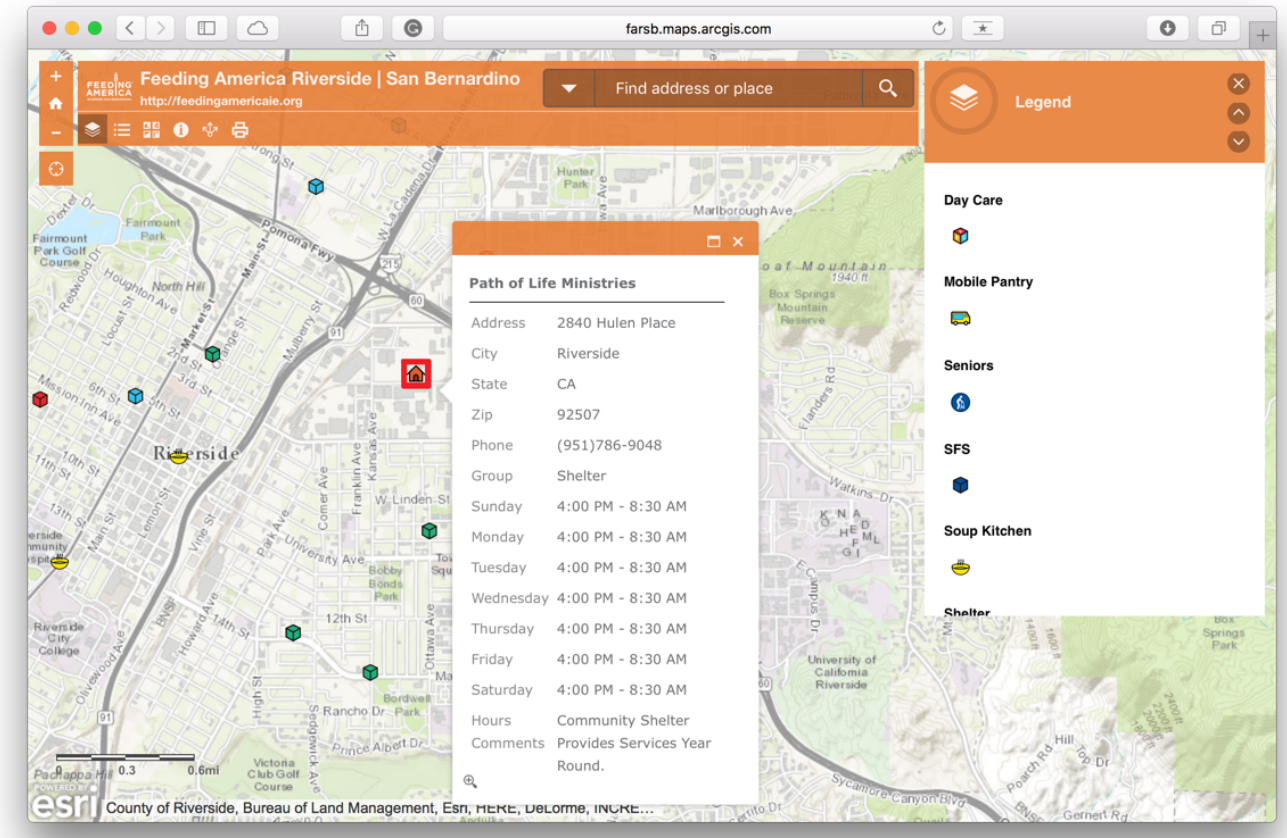

Figure 6-11: The pop-up window of the agencies story map.

The header contains FARSB's name, website link and logo on the top left side, and the search bar is next to them. The search bar enables the end user to search for an agency by different parameters: agency name, address, city, ZIP code, phone number, or group type (Figure 6-12). When the user types any of the parameters, a drop-down list appears with up to 15 suggestions to facilitate the search. 


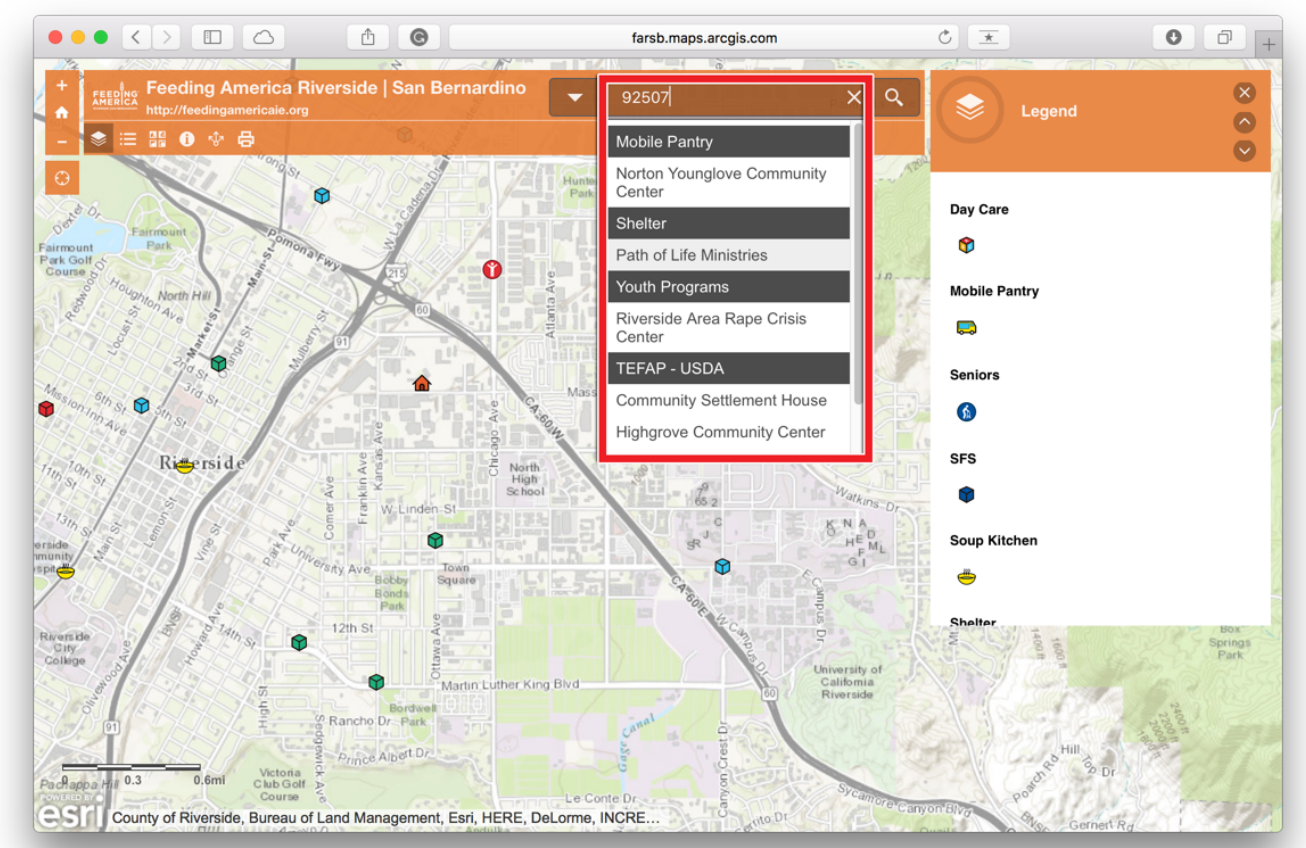

Figure 6-12: The search bar with a suggestions list.

Additionally, under the header, there is a toolbar that contains icons of six tools: Legend, Layers, Basemap gallery, Details, Share, and Print. Once the user clicks on any icon in the toolbar, the contents of the right panel will change to display that tool. The active tool at the startup of the story map is Legend. It duplicates the icons' appearance on the map when zooming in and out, and the name of the group type appears above each icon, as shown in Figures 6-9 and 6-10. The Layers tool enables the end user to hide the agencies of any group by unchecking that group on the right panel. Figures 6-13 and 6-14 illustrate the map before and after hiding types of the agencies. 


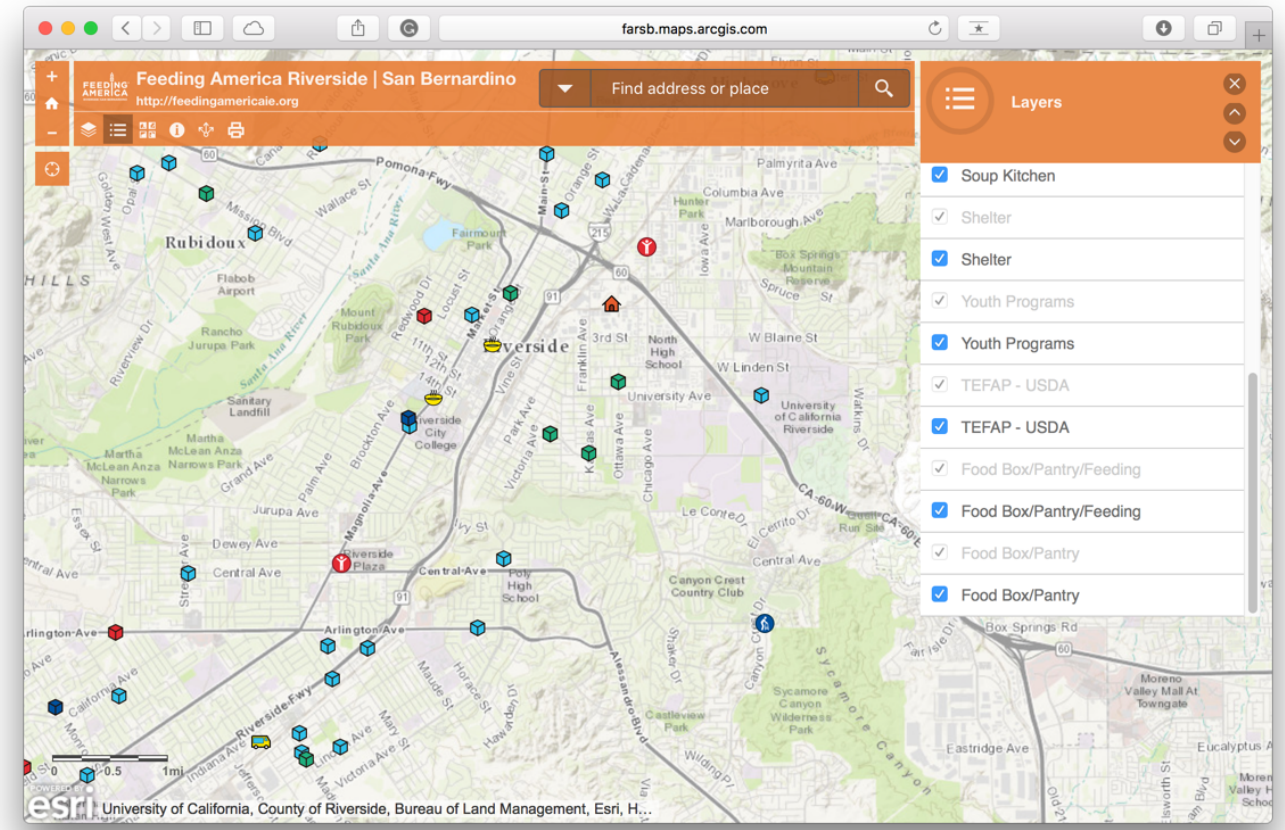

Figure 6-13: The agencies story map with all layers checked.

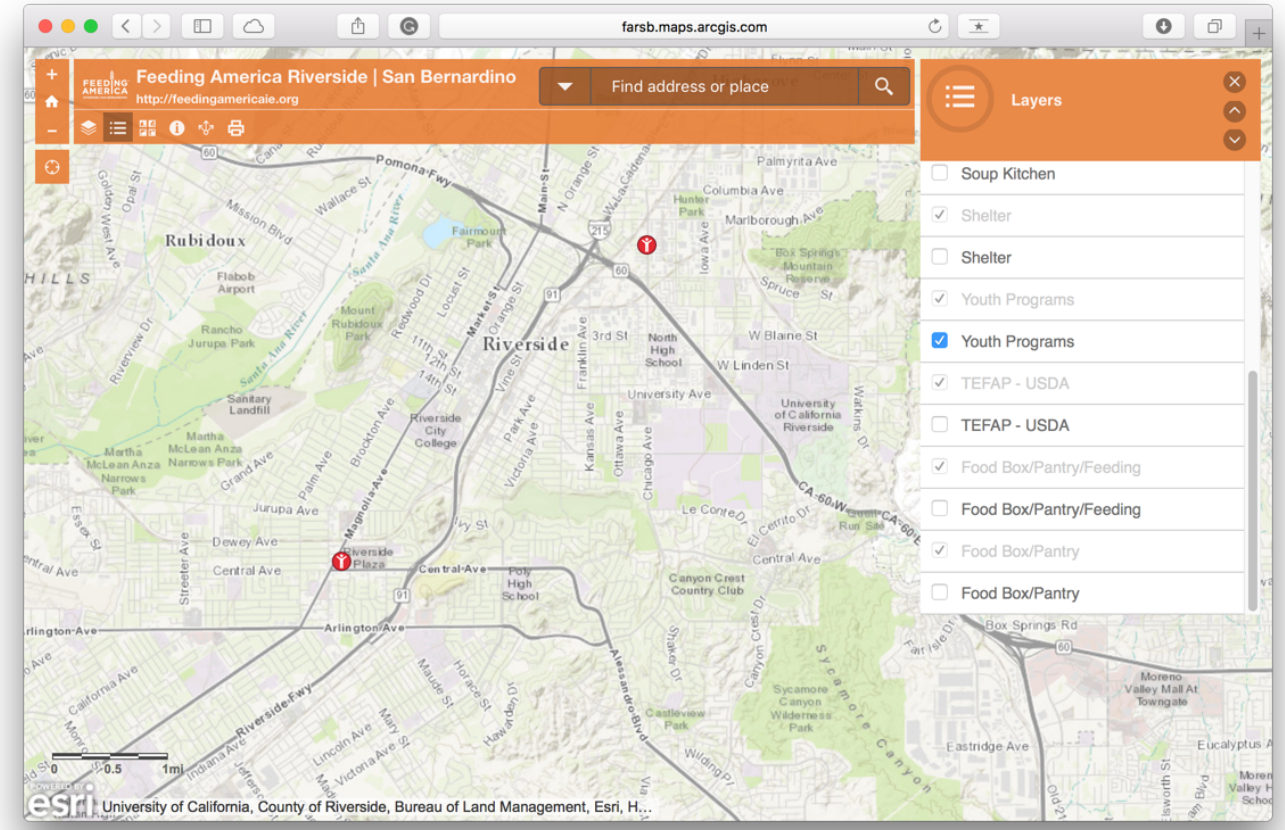

Figure 6-14: The agencies story map with layers hidden. 
The Basemap gallery (Figure 6-15) includes 12 basemaps that allow the end user to change the default basemap.

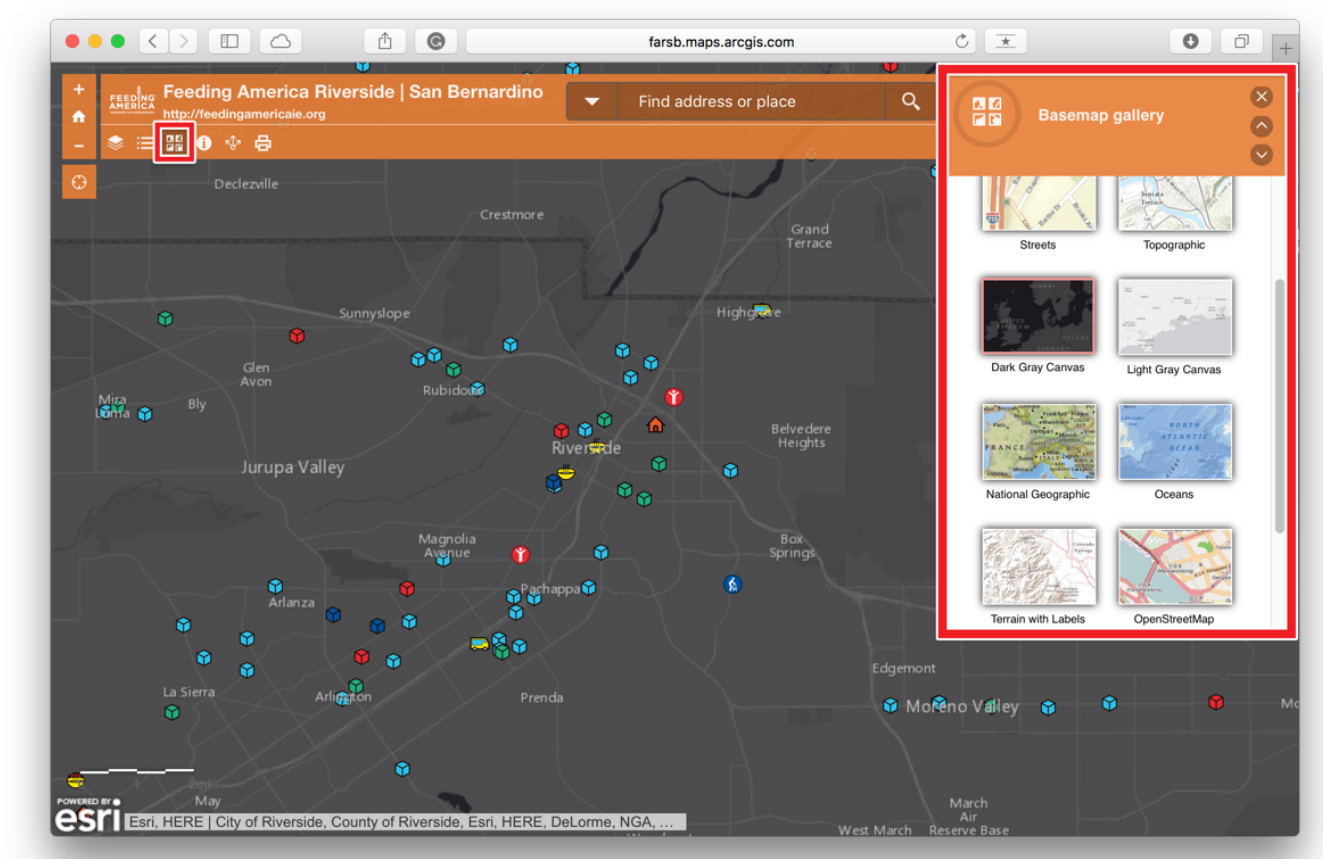

Figure 6-15: The Basemap gallery tool of the agencies story map.

The Details tool shows narrative information about the FARSB, as shown in Figure 6-16. The Share tool enables the end user to share the story map via Facebook, Twitter, Google Plus, and email, as illustrated in Figure 6-17. The Print tool allows the end user to print the map, with the ability to specify a title and add the legend (Figure 6-18). 


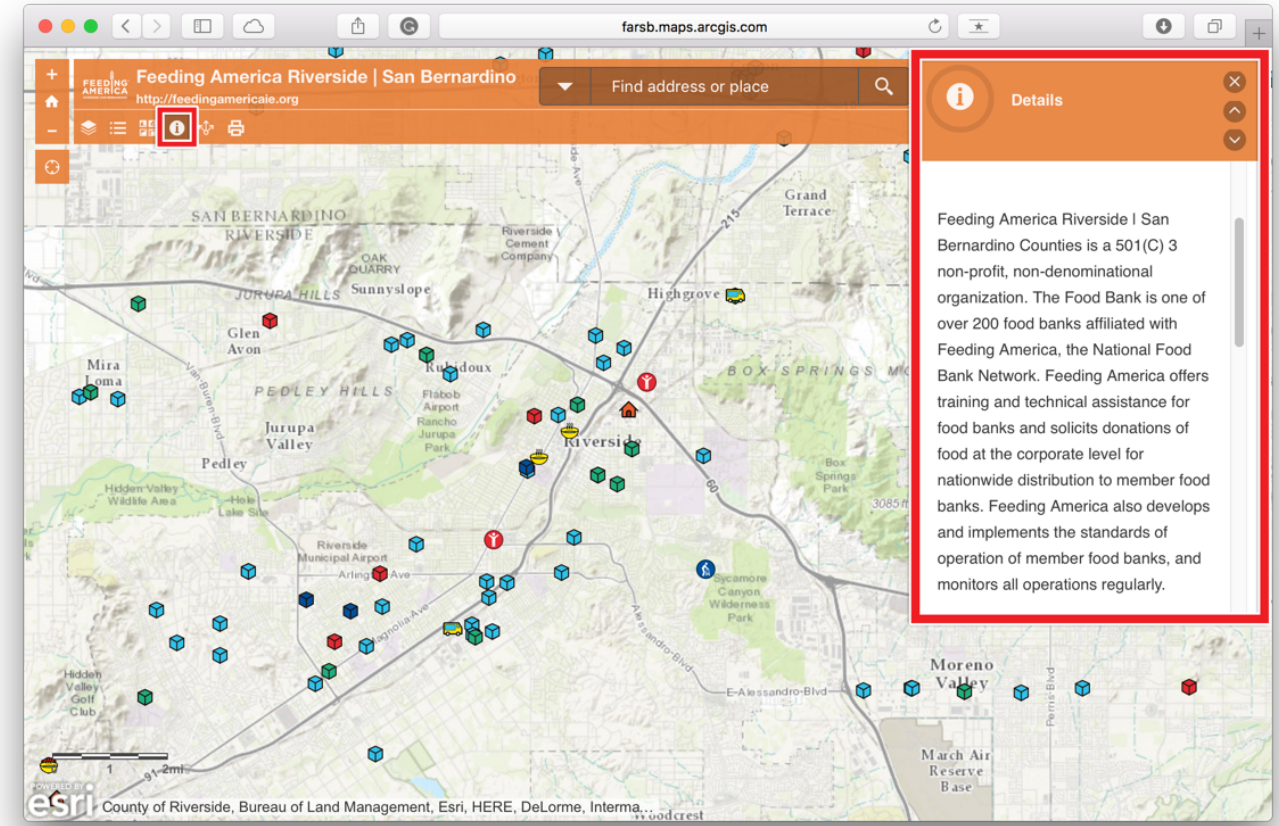

Figure 6-16: The Details tool of the agencies story map.

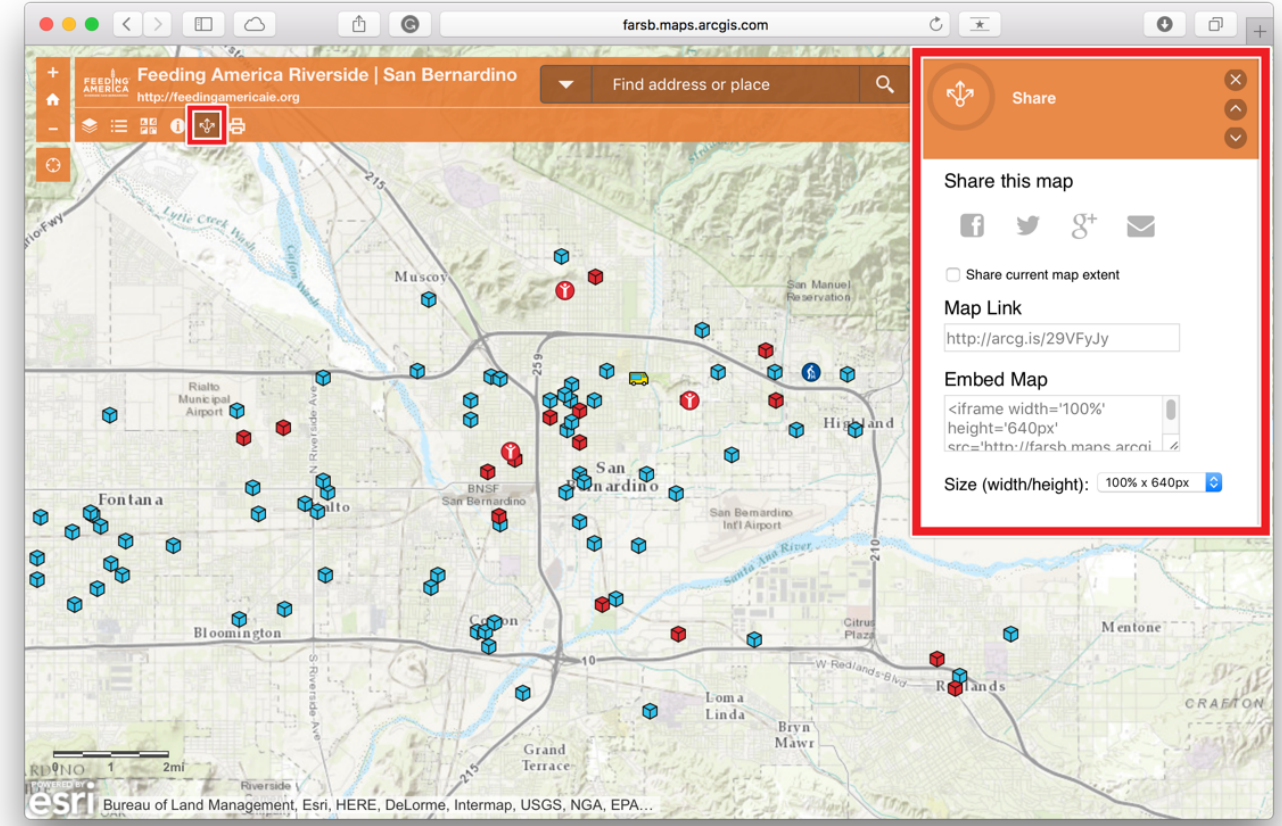

Figure 6-17: The Share tool of the agencies story map. 


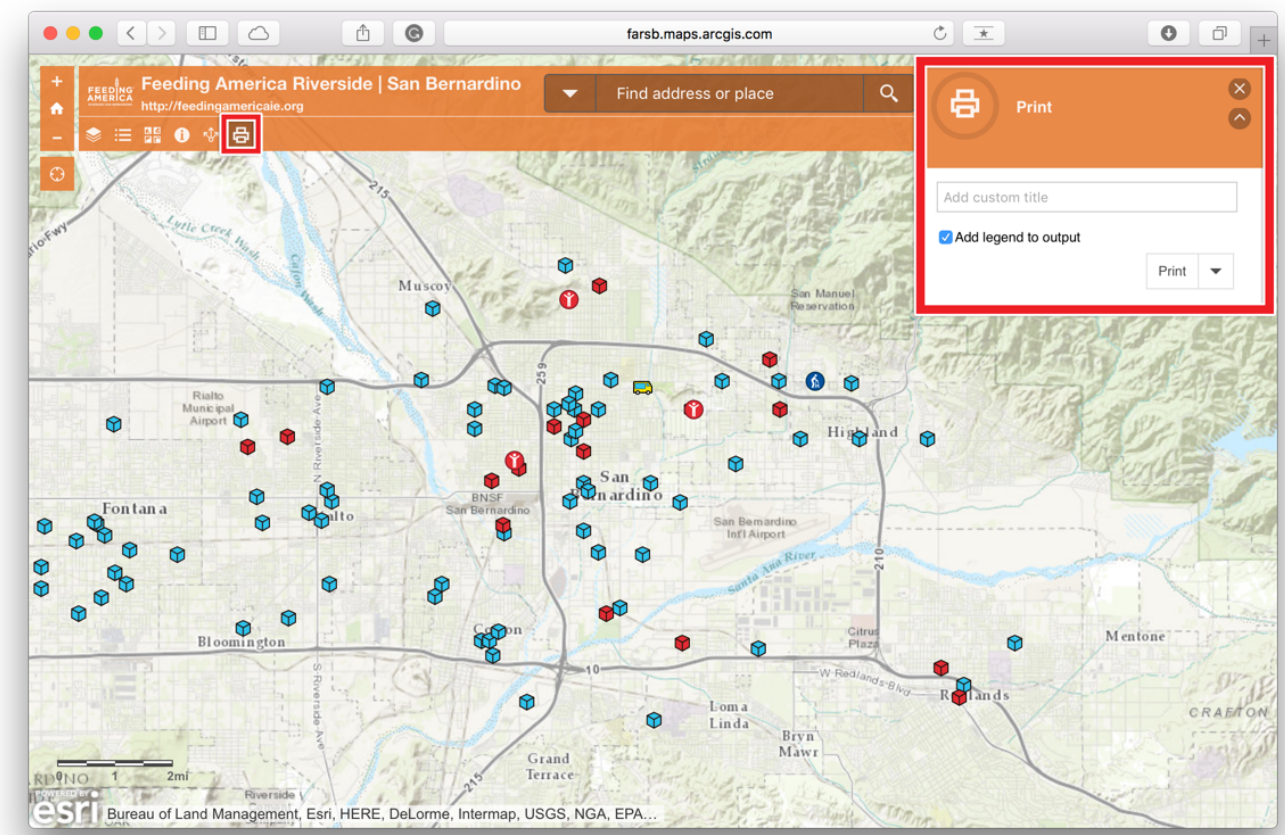

Figure 6-18: The Print tool of the agencies story map.

To summarize, this story map can help people in need find the agencies within their neighborhood. Furthermore, the story map has a variety of tools that enable the end user to access, view, and interact with the agencies' information.

\subsection{Summary}

The final results and analysis were described in this chapter in three main sections. Each section discussed how the FARSB could take advantage of the results in order to achieve its goals. Section 6.1 discussed the results and benefits of the analysis implemented in this project. Sections 6.2 and 6.3 discussed the story maps' interfaces and functions as well as the benefits to be gained from the story maps. 


\section{Chapter 7 - Conclusions and Future Work}

This chapter discusses the project conclusion in section 7.1. Then, section 7.2 proposes some concepts to improve this project and some other ideas for improving the efforts of the Feeding America Riverside | San Bernardino (FARSB) in order to eliminate hunger in the Inland Empire.

\subsection{Project Conclusion}

This project satisfied the goals and requirements that were agreed upon by the client, the advisor, and the MS GIS Program faculty at the University of Redlands. Three essential questions were successfully analyzed and addressed in this project:

- Where is the optimal site to establish a second warehouse?

- Where are the areas of greatest need and potential donors?

- Where are the agencies of the FARSB located?

This project addressed the first question and identified the optimal location for a supplemental food distribution center, based on the determined requirements and analysis. Consequently, the client planned to establish a second warehouse where the project indicated to expand food distribution. The second question was addressed, and a story map was created. The client was provided with a web application to display particular information about the Inland Empire in order to help increase the success of fundraising. The third question was addressed by the creation of another web application in order to display the agencies' locations and information. The client wanted people in need to be able to locate the organization's agencies within their neighborhood in order to be given food and assistance. All three questions were addressed to achieve the most significant goals of the FARSB; to eliminate hunger in the Inland Empire and to give everyone there access to healthy and affordable food.

\subsection{Future Work}

The geodatabase that was created in this project could be improved by using several concepts to achieve the maximum benefit for the FARSB. If the FARSB decided to expand and establish a third warehouse, it would be advantageous to identify the best location from among the eight candidates already determined by using the geodatabase that was created in this project. Subsequently, the geodatabase could be helpful toward creating a fleet management system in order to find the best routes for food delivery from each of the warehouses to the agencies. Another concept is to analyze the coverage of each agency to decide whether there is a need for new agencies to serve more people. The agencies web application could be improved by including a volunteered geographic information (VGI) functionality. This would help any new agency by adding its location and information to the application; also, that would allow the agencies to edit and update their information, if needed, in order to keep the application up to date for the people in need. 



\section{Works Cited}

Anness, K. (2014). Customize your story map app. ArcUser. Retrieved from http://www.esri.com/esri-news/arcuser/summer-2014/customize-your-story-map$\underline{\mathrm{app}}$

Bell, J. (2014, July 22). Global poverty [Web mapping application]. Retrieved from https://www.arcgis.com/home/item.html?id=3b502ce450414dc29eff9c68a4c982a $\underline{6}$

Brooks-Gunn, J. Duncan, G. J. (1977). The effects of poverty on children [Abstract]. The Future of Children, 7(2), 55. doi: 10.2307/1602387

Esri. (2013). What can you do with a story map? ArcUser. Retrieved from http://www.esri.com/esri-news/arcuser/summer-2013/what-can-you-do-with-astory-map

Esri. (2016a). Case studies. In Are there suitable sites for a distribution center? Retrieved from http://desktop.arcgis.com/en/analytics/case-studies/are-there-suitable-sitesfor-a-distribution-center.htm

Esri. (2016b). Case studies. In Which parcels are suitable sites for a fire station?

Retrieved from http://desktop.arcgis.com/en/analytics/case-studies/which-parcelsare-suitable-sites-for-a-fire-station.htm

Esri. (2016c). Case studies. In Which site for the new station maximizes fire protection coverage? Retrieved from http://desktop.arcgis.com/en/analytics/casestudies/which-site-for-the-new-station-maximizes-fire-protection-coverage.htm

Esri. (2016d). Case studies. In Which watersheds are grazing allotments in? Retrieved from http://desktop.arcgis.com/en/analytics/case-studies/which-watersheds-aregrazing-allotments-in.htm

Feeding America Riverside San Bernardino. (2016). About US. Retrieved from http://feedingamericaie.org/about-us/

Feeding America Riverside San Bernardino. (2016). Our History. Retrieved from http://www.feedingamerica.org/about-us/about-feeding-america/our-history/

Fu, P. (2015). Getting to know web gis. Redlands, CA: Esri Press.

Harder, C. (Eds.) (2015). The arcgis book: 10 big ideas about applying geography to your world. Redlands, CA: Esri Press.

Hernández, T., \& Bennison, D. (2000). The art and science of retail location decisions [Abstract]. International Journal of Retail \& Distribution Management 28(8), 357-367 
Herries, J. (2014, May 23). Ratio of households living above and below the poverty line [Web mapping application]. Retrieved from

http://univredlands.maps.arcgis.com/home/item.html?id=62ec1c03c1 ca49438d9a 53da4a6433b6

Li, X., Zhao, Z., Zhu, X. \& Wyatt, T. (2011). Covering models and optimization techniques for emergency response facility location and planning: a review. Math Meth Oper Res, 74, 281-310. doi:10.1007/s00186-011-0363-4

Story Maps Team. (2015, September 9). The living wage map [Web mapping application]. Retrieved from http://www.arcgis.com/home/item.html?id=703e7a35efa34cb893ff9872094319e4

Tong, D., Ren, F., Mack, J. (2012). Locating farmers' markets with an incorporation of spatio-temporal variation. Socio-Economic Planning Sciences, 46(2), 149-156.

Trinh, A. (2014, October 14). Story map - poverty and education [Web mapping application]. Retrieved from

http://www.arcgis.com/home/item.html?id=7a188c48847546ecbfbfbe7d36fa7c0b 
